Geological Society, London, Special Publications

New faults v. fault reactivation: implications for fault cohesion, fluid flow and copper mineralization, Mount Gordon Fault Zone, Mount Isa District, Australia

G. S. Nortje, N. H. S. Oliver, T. G. Blenkinsop, et al.

Geological Society, London, Special Publications 2011; v. 359; p. 287-311 doi: $10.1144 /$ SP359.16

$\begin{array}{ll}\begin{array}{l}\text { Email alerting } \\ \text { service }\end{array} & \begin{array}{l}\text { click here to receive free e-mail alerts when new } \\ \text { articles cite this article }\end{array} \\ \begin{array}{l}\text { Permission } \\ \text { request }\end{array} & \begin{array}{l}\text { click here to seek permission to re-use all or part of } \\ \text { this article }\end{array} \\ \text { Subscribe } & \begin{array}{l}\text { click here to subscribe to Geological Society, } \\ \text { London, Special Publications or the Lyell Collection }\end{array}\end{array}$

Notes

Downloaded by guest on December 4, 2011

(C) The Geological Society of London 2011 


\title{
New faults v. fault reactivation: implications for fault cohesion, fluid flow and copper mineralization, Mount Gordon Fault Zone, Mount Isa District, Australia
}

\author{
G. S. NORTJE ${ }^{1 *}$, N. H. S. OLIVER ${ }^{1}$, T. G. BLENKINSOP ${ }^{1}$, D. L. KEYS ${ }^{1}$, \\ J. G. MCLELLAN ${ }^{1} \&$ S. OXENBURGH ${ }^{2}$ \\ ${ }^{1}$ Economic Geology Research Unit and Predictive Mineral Discovery Co-operative Research \\ Centre (pmd $\left.{ }^{*} C R C\right)$, School of Earth and Environmental Sciences, James Cook University, \\ Townsville, QLD 4811, Australia \\ ${ }^{2}$ Aditya Birla Minerals Ltd, PO Box 3074, Adelaide Terrace, Perth, WA 6832, Australia \\ *Corresponding author (e-mail:fortbinder@gmail.com)
}

\begin{abstract}
Fluid flow leading to mineralization can occur both on newly formed faults and on faults that are reactivated subsequent to their initial formation. Conventional models of fault reactivation propose that, under high pore-fluid pressures, misorientated faults may reactivate due to low fault cohesion. Timing and orientation data for a mineralized Palaeo- to Mesoproterozoic terrain (Mount Gordon Fault Zone (MGFZ)) indicate that multiple successive new orientations of predominantly strike-slip faults developed (between 1590 and $c$. $1500 \mathrm{Ma}$ ), requiring that during the younger deformations some earlier formed faults were too cohesive and/or had insufficient pore-fluid pressures (or other potential fault-weakening effects) to induce reshear. Low porefluid pressures were probably not to blame for failed reactivation on all older faults because some young faults did form or reactivate due to high pore-fluid pressures, as evidenced by jigsaw-fit dilatant breccias, hypogene copper mineralization in veins and breccia infill, and subvertical tensile quartz veins aligned subparallel to $\sigma_{1}$. The assumption that old faults consistently have little or no cohesion appears to be incorrect in this terrain. Many older faults display prominent quartz veins along their length, which may explain this conclusion. Furthermore, faults with high cohesion may have acted as barriers and compartments, so that intersections between them and newly formed faults host mineralization, not because of reactivation, but because of interaction between new faults and cohesive materials defined either by fault precipitates or rock juxtaposition. Together, these results and observations provide new, simple tools to stimulate copper exploration within the region and in fault-hosted terrains.
\end{abstract}

The Proterozoic Mount Isa Block of northwestern Queensland, Australia is richly endowed with epigenetic, fault-related copper mineralization, including the world-class Mount Isa copper ore bodies. However, because of the immediate proximity of the Mount Isa copper deposits to equally large lead-zinc ores, controversy has surrounded their interpretation (Perkins 1984, 1989, 1990, 1997; Swager 1985; Swager et al. 1987; Bell et al. 1988; Heinrich \& Cousens 1989; Bell 1991; Heinrich et al. 1995; Davis 2004; Wilde et al. 2006). To the north of the major deposits of the Mount Isa Valley (Fig. 1), the Mount Gordon Fault Zone (MGFZ) stretches more than $100 \mathrm{~km}$ northwards and contains excellent examples of fault-related copper mineralization, in most cases without attendant lead-zinc. In particular, the Mammoth (formerly 'Gunpowder') deposits lie on apparent ENE-trending splays of the MGFZ (Scott \& Taylor 1982; Richardson \& Moy 1998), and are dominated by fault- and hydrothermal breccias in quartzite and siltstone units of the Myally Subgroup (Alsace Quartzite, Bortala Formation, Whitworth Quartzite).

The region north of Mount Isa has been important for reconstructions of the structural and tectonic evolution of the Mount Isa Block because of the excellent outcrop, the relatively low metamorphic grade (up to lower greenschist) and modest ductile strains imposed by the approximately 1600 $1500 \mathrm{Ma}$ Isan Orogeny. Reconstructions of the earliest basin-forming events have included recognition of several growth faults and a northwardtrending rift (Derrick 1982; O'Dea et al. 1997; Betts 1999, 2000; Betts et al. 2003; Gibson 2005) including the oblique Mount Gordon Arch. The effects of the Isan Orogeny included north-south contraction, possibly with south-directed thrusting (Bell 1983) and east-west shortening, the latter reflected by folding and some foliation development 


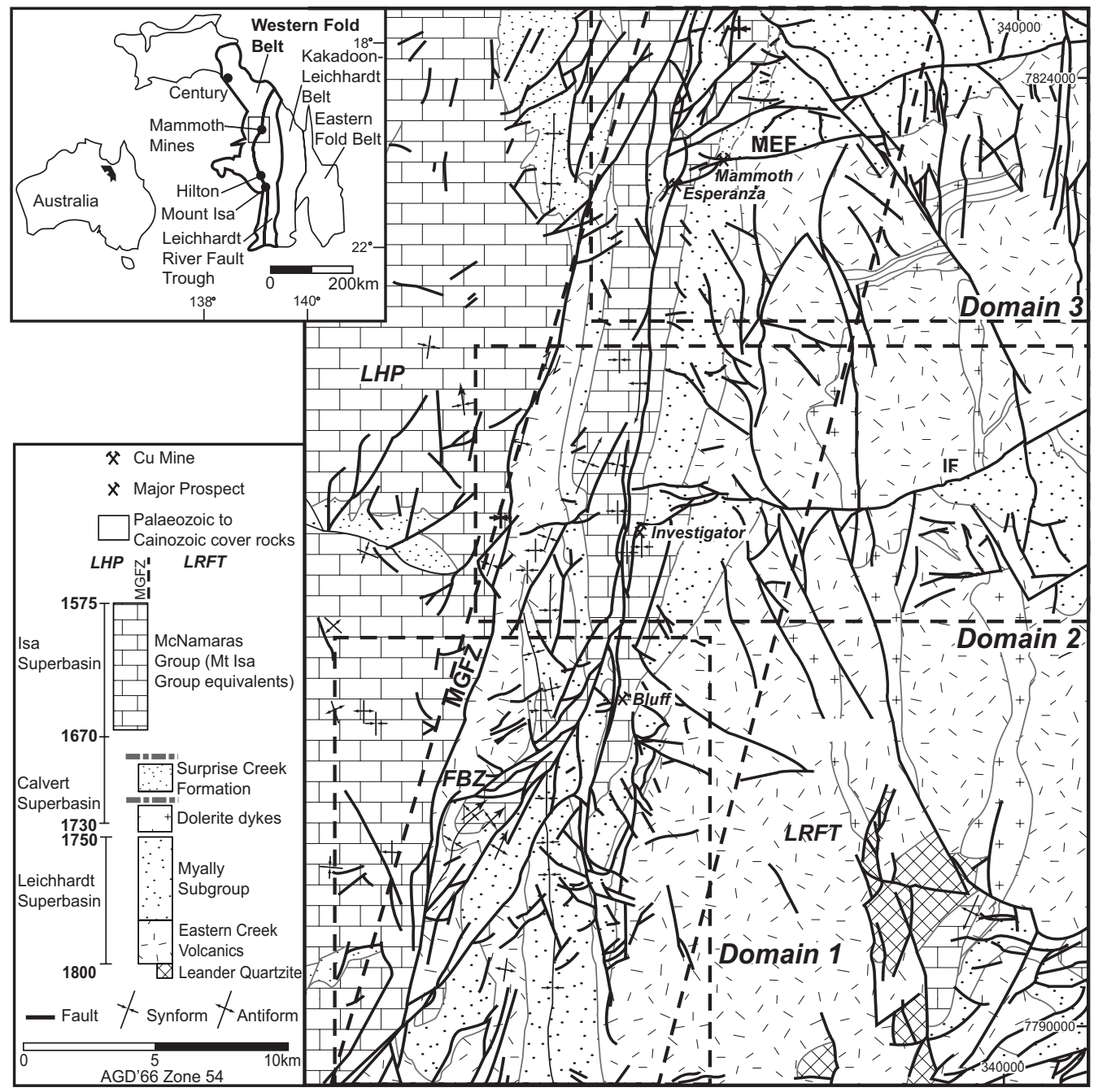

Fig. 1. The study area used for relative age analysis, with general geology, major fault zones (faults), major structures (folds), major mineral deposits and prospects. Domains 1-4 are indicated. Domain 1 is the southern half of the MGFZ; Domain 2 is the Investigator Fault Zone; Domain 3 is the Mammoth (Gunpowder) Mines region; and Domain 4 is the MGFZ. Abbreviations are as follows: LHP, Lawn Hill Platform; LRFT, Leichhardt River Fault Trough; MEF, Mammoth Extended Fault; IF, Investigator Fault Zone; MGFZ, Mount Gordon Fault Zone; FBZ, Fort Binder Fault Zone. Inset shows the location of the Mount Isa Inlier and regional tectonostratigraphical units (note WFB). Projection AGD 1966, zone 54 modified from Hutton et al. (1985).

(O’Dea \& Lister 1995; O’Dea et al. 1997). Bell (1983) proposed, however, that no former rift architecture was required to explain the geometric details of the thrust array, which has been disputed by other researchers because of the ready recognition of criteria for growth faults and normal faults (Derrick 1982; O'Dea \& Lister 1995; O'Dea et al. 1997). With a few local exceptions (see later), most workers also have not considered the detail of the $10 \mathrm{~m}$ - to $\mathrm{km}$-scale fault orientations nor the field-based evidence for their movement sense or potential reactivation, both of which we attempt to address here. Late in the Isan Orogeny, a large sinistral wrench system developed (Lister et al. 1986, 1987, 1999; O’Dea \& Lister 1995; O’Dea et al. 1997), when most of the fault-related copper appears to have been introduced (Keys 2008).

At the core of the above-mentioned controversy in the overall interpretation of the architectural and kinematic elements is uncertainty regarding the 
process of fault reactivation, along with parallel questions (particularly at Mount Isa) regarding the possibility of early base-metal mineralization and its potential 'remobilization' into favourable latetectonic fault structures. Here, we assemble and compare the previous work on the geometric and kinematic evolution of the MGFZ, and add new field data on the history of fault activation and reactivation. Several key questions will be addressed.

- Which fault segments within either the early rifting (' $D_{\mathrm{e}}$ ') or north-south convergence $\left(' D_{1}^{\prime}\right)$ events developed and retained orientations that were favourable for further fault slip during the later wrenching ( $\mathrm{D}_{3}$ or $\mathrm{D}_{4}$ ')?

- What were the combinations of far-field stresses and pore-fluid pressures that led to fault reactivation and new fault development during $\mathrm{D}_{3}$ or $\mathrm{D}_{4}$ ?

- How did all of the above combine to result in the presently observed distribution and styles of epigenetic copper mineralization formed during wrenching?

The aims of this analysis is to understand whether there is a firm basis for simply utilizing the known orientations of faults (of any timing) to predict the location of potentially undiscovered mineralization, a technique that is commonly used elsewhere, particularly in predictive numerical analysis of fault arrays (Holyland \& Ojala 1997; Mair et al. 2000; Ojala \& Nykänen 2007; McLellan \& Oliver 2008). McLellan \& Oliver (2008), for example, successfully predicted the location of the majority of epigenetic $\mathrm{Cu} \pm \mathrm{Au}$ deposits and prospects in the Eastern Fold Belt of the Mount Isa Block by assuming that the presently observed fault architecture could be used as a template for a numerical simulation, and applying small strains to this fault array. However, although details of the fault evolution were considered in part, this style of analysis places little emphasis on the locations of earlier structures and also of early mineralization unrelated to the late-Isan faulting, several examples of which are recognized in the Eastern Fold Belt (Oliver et al. 2008). Here we make some simple, conservative assumptions about fault-reactivation potential, then test the veracity of such assumptions by a spatial analysis and more detailed examination of anomalous results, particularly those situated at or near mineral deposits. The specific locations of mineral deposits in the MGFZ and elsewhere in the Mount Isa Block may relate to a protracted geometric evolution in a systematic way, rather than simply being on any fault of any previous age, reactivated or precipitated during the latest deformation event. Our analysis may thus assist with the distinction between earlier mineralization, whose present distribution reflects $100 \mathrm{~m}$ - to $\mathrm{km}$-scale redistribution near the sites of former syngenetic or diagenetic mineralization (related to rift faults), and latetectonic deposits localized on faults and apparently independent of any earlier ore accumulations.

\section{Summary of regional geology relevant to mineralization}

The Mount Isa Block (Fig. 1) has undergone a complex protracted deformation and metamorphic history related to cycles of extension and shortening from 1800 to $1500 \mathrm{Ma}$ (Derrick 1982; Blake 1987; Etheridge et al. 1987; Blake \& Stewart 1992). Here we focus on aspects of the faulting history pertinent to understanding the geometric and kinematic history that led to localization of copper deposits along and around faults within the Western Fold Belt (WFB) (Fig. 1). There are several main stages of interest.

\section{Early stage}

Rifting, basin formation and sedimentation, in particular the Leichhardt (c. 1800-1740 Ma), the Calvert (c. 1730-1670 Ma) and the Isa (c. 1670$1575 \mathrm{Ma}$ ) superbasins, all of which are still variably preserved to some extent in the Leichhardt River Fault Trough (LRFT) of the Mount Isa Block including the MGFZ (Fig. 1) (Neumann et al. 2006; Gibson et al. 2008).

\section{Mid stage}

Three main deformational events during the Isan Orogeny $\left(D_{1}, D_{2}, D_{3}\right)$ in the western Mount Isa Block. There is no universally accepted model for post-depositional deformation within the Mount Isa Block or the WFB (Fig. 1) (Derrick 1982; Bell 1983, 1991; Blake 1987; Blake \& Stewart 1992; Nijman et al. 1992a, b; Stewart 1992; O'Dea \& Lister 1995). The 1:250 000- and 1:100 000-scale maps can be interpreted to show that the original rift geometry is preserved and that the basement structures played an important part during the rifting process as well as in the postdepositional deformation of the region. $\mathrm{D}_{1}$, the first deformational event, has been described as southwards-directed thrusting that produced eastwest-orientated folds (Bell 1983). However, the presence of $\mathrm{D}_{1}$ has been widely debated (Derrick 1982; Bell 1983; O’Dea \& Lister 1995). The main deformational event $\left(\mathrm{D}_{2}\right)$ during the Isan Orogeny and the peak of metamorphism has been suggested to have taken place at around $1595-1580 \mathrm{Ma}$ (Rubenach et al. 2008) and appears to have been an inlier wide east-west shortening event. Slightly later in the deformational history, an ENEshortening $\left(\mathrm{D}_{3}\right)$ event occurred, at approximately 
$1550 \mathrm{Ma}$ (Bell 1983; Rubenach et al. 2008), and was interpreted to have been responsible for the reactivation of many major $\mathrm{D}_{2}$ structures.

\section{Late stage}

Miller (2007) at the Mount Isa Copper deposit has indicated that the orientation of the stress regime during brecciation and $\mathrm{Cu}$ mineralization was likely to have been with $\sigma_{1}$ in the NW quadrant with a shallow plunge, as also suggested by Keys (2008). This $\mathrm{D}_{4}$ deformation, the absolute timing of which is not well constrained in the WFB, resulted primarily in the strike-slip reactivation of major steeply dipping faults, the formation of new faults, including north-south-striking faults with sinistral strike-slip displacement, and brecciation and mineralization across the Mount Isa Block (Keys 2008). Although timing of $\mathrm{D}_{4}$ is poorly constrained in the study area, a strong association of similar (orientation, shear sense and fault infill) faults, breccias and late tectonic granites in the Eastern Succession occurred at about $1527 \mathrm{Ma}$ (Keys 2008; Rubenach et al. 2008). The Ernest Henry ore body, some regional sodic-calcic alteration and many small copper deposits were formed by fault-related fluid flow at this time in the Eastern Succession (Oliver et al. 2004, 2008; Rubenach 2005; McLellan \& Oliver 2008). However, recent $\mathrm{Re}-\mathrm{Os}$ work has suggested that an event around 1350 Ma may have been important, including dates on chalcopyrite from the Mount Isa copper deposit (Gregory et al. 2008) and on molybdenite from the Merlin deposit near Starra (Duncan et al. 2009). It is possible that $\mathrm{D}_{4}$ relates to this age rather than to the end of the Isan Orogeny, although more work is required.

\section{Analysis of fault timing and orientation}

Fluid flow leading to mineralization can occur both on newly formed faults and on faults that are reactivated subsequent to their initial formation (Sibson 1977, 1989, 1996, 2000, 2001; Cox et al. 2001; Kolb et al. 2004; Micklethwaite et al. 2010). In the Eastern Fold Belt, Oliver et al. (2008) demonstrated that copper mineralization occurred over a long period ( $\geq 100 \mathrm{Ma}$ ). Therefore, the assumption that all mineralization occurred superimposed on the post-Isan fault geometry is incorrect, despite a reasonably high convergence of numerically predicted zones of low differential and mean stress, and the known sites of copper mineralization, both at Mount Isa and other locations with a protracted structural history (Ojala \& Nykänen 2007; McLellan \& Oliver 2008).

In order to try to assess the possible role of protracted fault evolution on the localization of mineralization, we have attempted to reconstruct the sequence of faulting events, the change in geometries with time and the relative importance of new v. reactivated faults at different stages in the overall evolution of the LRFT. This is directed towards trying to understand whether the early elements of the rift architecture were crucial for the subsequent introduction of copper, or not.

The overall approach we have taken is as follows.

- Divide the MGFZ up into four subdomains to undertake a 'relative age analysis' (Fig. 1).

- Measure the orientation and length of all the faults and classify them according to their orientation using a length-weighted criterion on rose diagrams where the frequency is multiplied by the length of the fault segment (Fig. 2). In Figure 2, the longer petals of the rose diagram reflect longer fault segments: for example, NE-trending fault segments are longer in domain 1 (Fort Binder Fault Zone) (Fig. 2a). Faults were then classified into subsets based on the above criterion using letters $A, B, C, D$, $E, F, G$.

- Use a simplistic overprinting criterion to make a preliminary interpretation of the relative timing (a)

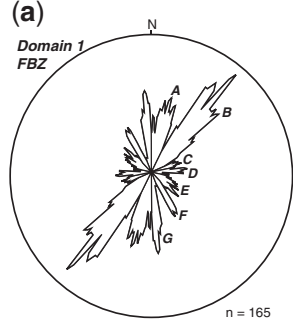

(c)

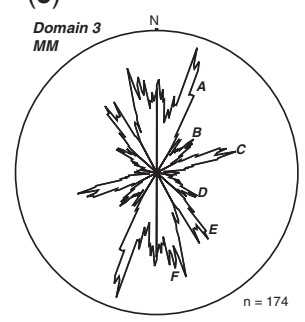

(b)

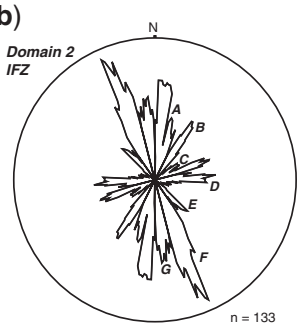

(d)

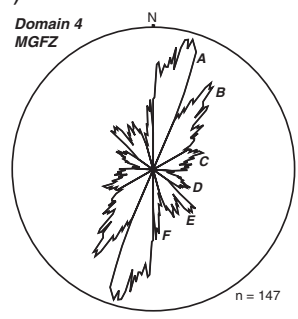

Fig. 2. Rose diagrams showing the length-weighted orientation of the four domains within the study area. (a) Domain 1, Fort Binder Fault Zone (FBZ) comprising seven fault sets. (b) Domain 2, Investigator Fault Zone (IFZ) comprising seven fault sets. (c) Domain 3, Mammoth Mines region comprising six fault sets. (d) Domain 4, Mount Gordon Fault Zone (MGFZ) comprising six fault sets. Letters $A, B, C, D, E, F$ and $G$ define different fault sets belonging to each domain (and not necessarily correlating between domains). 
(a)

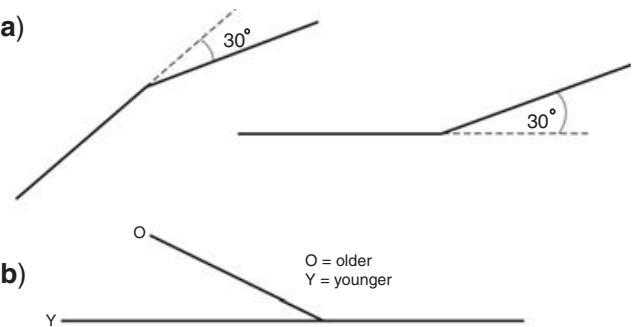

(c)

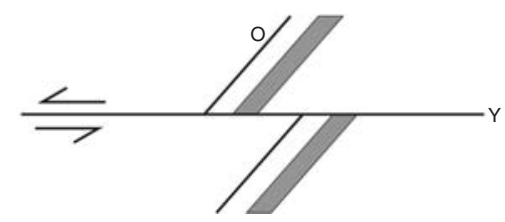

Fig. 3. Assumptions used to determine initial fault timing relationships. (a) A single fault bend. Null values were assigned to fault segments with angles of less than $30^{\circ}$. (b) ' $\mathrm{Y}$ ' junction where the shorter segment is older than the longer segment. (c) Apparent offset of either faults or bedding.

of intersecting faults based on their geometry (Fig. 3a-c). Faults, whose intersection angle was less than $30^{\circ}$, particularly where a possible displaced segment was not identified, were not included in the analysis, because these most probably represent fault-tip splays developed during one faulting event. Even if they are not synchronous splays, their omission does not greatly affect the conclusions.

- Apply the 'relative age table' approach of Angelier $(1991,1994)$ to define an apparent sequence of faulting events, and to establish clear $\mathrm{v}$. vague overprinting relations.

- Assess additional geological information (field relationships including the relationship of unconformities and folds to faults) to modify the preliminary sequence of faulting events.

- Identify and distinguish fault rotations and reactivations on early faults that have led to their reorientation (or preservation of initial orientation) along directions potentially suitable for mineralization.

\section{Binary chronological matrix analysis (relative age analysis)}

Extracting incremental stress and strain, and deformation histories, from final geometries is very difficult. Standard geological analysis techniques where cross-cutting relationships are observed can yield vague and uncertain deformation histories, the interpretation of which can be controversial (e.g. Bell 1983). Error can originate from unobserved rotations or displacements, the impossibility of determining unique strain histories from a single cumulative strain, and the variation of fault geometry and local kinematics at any one time, which may otherwise be interpreted as being the product of different events (Angelier 1991, 1994; Potts \& Reddy 1999, 2000; Forster \& Lister 2008).

Binary chronological matrix analysis, referred to as relative age analysis herein, is a form of combinatorial mathematics where successive permutations are carried over as large a data set as possible to obtain a relative chronology (Angelier 1991, 1994; Potts \& Reddy 1999, 2000). The datum is the order or succession of two or more geological events. For $n$ geological events there exist $n(n-1)$ relative chronologies (Angelier 1991, 1994; Potts \& Reddy 1999, 2000). For example, for three geological events, here termed $x, y$, and $z$, there are six possible relative chronologies that is $x y z, x z y, y x z, y z x, z x y$ and $z y x$ (Angelier 1991, 1994; Potts \& Reddy 1999, 2000). In the present case, a robust analysis of this type may lead to a clear chronology of different faults with different orientations. However, if many or most of the faults developed at the same time, as a network of faults with several different orientations (e.g. the fault-fracture network of Sibson 1996, 2001), then the chronological analysis would confirm mutual cross-cutting relationships of differently orientated faults because there would not be a clear chronology of different faults with different orientations.

This overall approach is similar to the approach of Forster \& Lister (2008) where tectonic sequence diagrams (TSDs) are used on an outcrop scale to determine the relative sequence of events without using a combinatorial mathematical framework. In their approach, a temporal sequence is inferred on an outcrop scale followed by selecting marker sequences and correlating between different TSDs (Forster \& Lister 2008). They also confirm absolute ages of events based on geochronology of a particular event; for example, using $\mathrm{Ar} / \mathrm{Ar}$ dating in the Otago schists, New Zealand.

The Angelier (1991, 1994), Potts \& Reddy (1999, 2000) and Forster \& Lister (2008) approaches are all advantageous because they remove $\mathrm{D}_{1}-\mathrm{D}_{n}$ nomenclature from conventional structural analysis and allow a more unambiguous approach to infer the structural evolution of a particular region. They also avoid the difficulty that arises from adding or subtracting a new $\mathrm{D}_{n}$ event to a $\mathrm{D}_{n}$ succession. One advantage of the combinatorial mathematics approach over the TSD method is that it forces the user to deal with contradictory observations, whereas the latter method does not explicitly address that particular problem. 


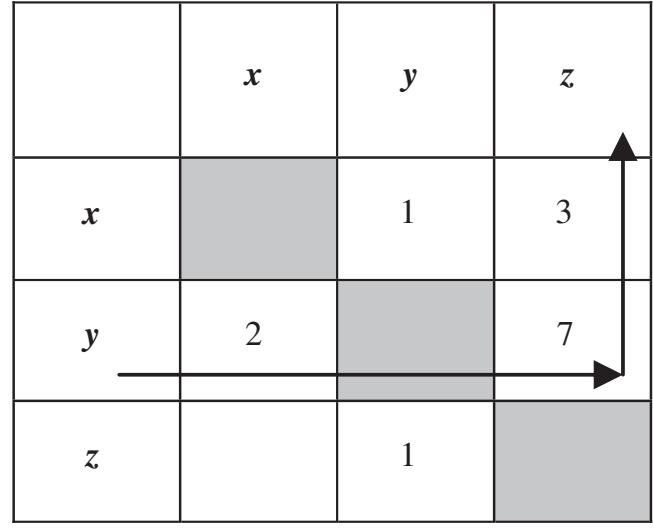

Fig. 4. Initial arbitrary binary chronological matrix where the figures are 'read' from row (oldest) to column (youngest), for example, seven observations are made where $y$ is older than $z$, and one apparent relationship where $\mathrm{z}$ is older than $\mathrm{y}$. The grey shading indicates relationships between events of the same timing and are assigned a null value in the analysis.

\section{Binary chronological matrix construction}

For the example above, the six relative chronologies are built into a matrix so that one line and one column with the same rank correspond to the same event (Fig. 4). The order of ranking is arbitrary because the order of events in unknown to begin with (Fig. 4) (Angelier 1991, 1994; Potts \& Reddy 1999, 2000).

\begin{tabular}{|l|l|l|l|}
\hline & $y$ & $x$ & $z$ \\
\hline$y$ & & 2 & 7 \\
\hline$x$ & 1 & & 3 \\
\hline$z$ & 1 & & \\
\hline
\end{tabular}

Fig. 5. Revised binary chronology in which successive permutations are calculated based on the count of relative ages. This output provides the best possible mathematical solution (Angelier 1991, 1994). Therefore consistent chronologies (top-right half of the figure) are $85 \%$, while inconsistent chronologies are $15 \%$; these statistics are included in the output of CHRONO.exe (Angelier 1992).
Once all observations have been inserted into the matrix (Fig. 4) then the data can be arranged into a temporal sequence (Fig. 5). This solution provides the best possible mathematical solution based on the combinatorial (factorial) approach (i.e. successions for $n$ events $n$ ! and $n(n-1)$ ) (Angelier 1991, 1992, 1994). However, relative age relationships that are 'less reliable' may emerge, in which the number of relationships where feature $x$ is older than feature $y$ is only slightly greater than relationships where $y$ is older than $x$. This may mean that a particular feature may have repeated or reactivated, or two completely unrelated features produce similar characteristics other than timing relationships (e.g. a fracture network with several strands of different orientations but the same timing). Thus, once an optimal solution is obtained it is advisable that other geological information is inserted into the matrix to obtain a better solution and one that is more geologically realistic (equivalent, for example, to the use of $\mathrm{Ar} / \mathrm{Ar}$ or other geochronological data in a structural history; Forster \& Lister 2008). The reliability of the position in the relative age table can be treated as an additional factor for subsequent analysis. All relative age analysis plots (binary chronological matrices) were generated using CHRONO.exe (Angelier 1992). Because the data set was so extensive (362 880 relative chronologies were possible), a computational approach was necessary.

\section{Initial orientation and relative age analysis}

The MGFZ region lies within the Western Fold Belt, and Mount Isa Inlier presents an excellent opportunity to study and test the use of relative age tables. Existing government geological mapping (Mammoth Mines, Sheet 6758) and field observations were used to generate binary chronological matrices (Figs $1 \& 6$ ) for interpreting the relative and absolute chronology of faulting within the area. The analysis was carried out in twodimensionally (2D) because most faults in their current configuration are steeply dipping, have apparent strike-slip offsets and locally show evidence of strike-slip displacements.

\section{Domain subdivision}

The study area was subdivided into four domains, based on the different styles and character of fault orientations, and lithological and stratigraphical patterns within the MGFZ. Domain 1 (Fort Binder Fault Zone, FBZ) comprises the southern half of the MGFZ (Fig. 1) and is host to seven fault sets based on orientation (Fig. 2a). The dominant rock 
Domain 1 (Fort Binder Fault Zone (FBZ))

(a)

\begin{tabular}{|c|c|c|c|c|c|c|c|c|c|}
\hline & $U n_{2}$ & $F n$ & $D$ & $B$ & $F$ & $C$ & $A$ & $E$ & $G$ \\
\hline$U n_{2}$ & & 4 & 3 & 7 & 3 & 4 & & 4 & 1 \\
\hline$F n$ & & & & 3 & 1 & & 2 & 1 & \\
\hline $\boldsymbol{D}$ & & & & 2 & & & & 1 & 1 \\
\hline $\boldsymbol{B}$ & & & & & 3 & 3 & 4 & 4 & 6 \\
\hline $\boldsymbol{F}$ & & & & 2 & & 1 & & 1 & \\
\hline $\boldsymbol{C}$ & & & & 3 & & & 3 & & 1 \\
\hline $\boldsymbol{A}$ & 1 & & & 2 & & 1 & & 8 & \\
\hline $\boldsymbol{E}$ & 2 & & & 4 & & 1 & 3 & & 6 \\
\hline $\boldsymbol{G}$ & & & & & & & 1 & 2 & \\
\hline
\end{tabular}

Inconsistent Chronologies $=22 \%$

Consistent Chronologies $=78 \%$

Domain 3 (Mammoth Mines Region (MM))

(c)

\begin{tabular}{|c|c|c|c|c|c|c|c|c|c|}
\hline & $U n_{2}$ & $U n_{1}$ & $F n$ & $D$ & $B$ & $F$ & $C$ & $A$ & $E$ \\
\hline$U n_{2}$ & & & & 3 & 2 & & 6 & & 4 \\
\hline$U n_{1}$ & & & & & 4 & & 8 & 2 & 4 \\
\hline$F n$ & & & & 1 & 4 & 4 & 3 & 6 & \\
\hline$D$ & & 1 & & & & 3 & 2 & 2 & 1 \\
\hline$B$ & & & & & & 5 & 1 & 5 & 1 \\
\hline F & & & & & 4 & & 3 & 1 & \\
\hline C & & & & 2 & & 2 & & 5 & 6 \\
\hline A & & & 1 & 1 & 2 & 1 & 3 & & 3 \\
\hline E & & & & 1 & & 1 & 2 & 2 & \\
\hline
\end{tabular}

Inconsistent Chronologies $=21 \%$
Domain 2 (Investigator Fault Zone (IFZ))

(b)

\begin{tabular}{|c|c|c|c|c|c|c|c|c|c|}
\hline & $U n_{2}$ & $F$ & $F n$ & $C$ & $G$ & $B$ & $A$ & $E$ & $D$ \\
\hline$U n_{2}$ & & & 1 & 3 & & 1 & & & 2 \\
\hline$F$ & & & 3 & 1 & & 3 & & & 2 \\
\hline$F n$ & & & & & & & & & \\
\hline$C$ & & & & & 2 & 1 & & & 2 \\
\hline$G$ & & & & 1 & & & & 5 & \\
\hline$B$ & & 1 & & & & & 1 & 1 & 2 \\
\hline $\boldsymbol{A}$ & & & & 1 & & 1 & & 1 & 3 \\
\hline $\boldsymbol{E}$ & & & & & & & & & 4 \\
\hline $\boldsymbol{D}$ & & 1 & & & 1 & 1 & & & \\
\hline
\end{tabular}

Inconsistent Chronologies $=15 \%$

Domain 4 (Mount Gordon Fault Zone (MGFZ))

(d)

\begin{tabular}{|c|c|c|c|c|c|c|c|c|c|}
\hline & $U n_{2}$ & $U n_{1}$ & $F n$ & $E$ & $C$ & $B$ & $A$ & $D$ & $F$ \\
\hline$U n_{2}$ & & & & 3 & 6 & 3 & & 6 & \\
\hline$U n_{1}$ & & & 5 & 10 & 15 & 14 & 3 & 7 & 1 \\
\hline$F n$ & & & & 3 & 2 & 5 & 5 & 2 & \\
\hline$E$ & & & & & 2 & 4 & 11 & 1 & \\
\hline $\boldsymbol{C}$ & & & & & & 6 & 9 & 5 & 4 \\
\hline $\boldsymbol{B}$ & & & & 6 & 4 & & 15 & 6 & 6 \\
\hline $\boldsymbol{A}$ & & & & 4 & 4 & 2 & & 7 & \\
\hline $\boldsymbol{D}$ & & & 3 & & 1 & 6 & 2 & & 7 \\
\hline $\boldsymbol{F}$ & & & 3 & & & 2 & 1 & 2 & \\
\hline
\end{tabular}

Inconsistent Chronologies $=19 \%$

Fig. 6. Relative chronological matrix analysis values for: (a) Domain 1 (FBZ); (b) Domain 2 (IFZ); (c) Domain 3 (MM); and (d) Domain 4 (MGFZ). (a)-(d) also show the percentage of inconsistent and consistent chronologies at the bottom. These values are the output provided by CHRONO.exe (Angelier 1992). $\mathrm{Un}_{1}$, Myally-Surprise Creek unconformity; $\mathrm{Un}_{2}$, Myally-McNamaras Group unconformity; $\mathrm{F}_{n}$, folding.

types in the area are basalts of the Eastern Creek Volcanics, quartzites of the Myally Subgroup and black shales of the McNamara Group. Here faults typically trend NNE, NE, east-west and ESE, and are mostly subvertical. Most faults have a dominant strike-slip separation (Fig. 1). The longer fault segments within this domain trend $\mathrm{NE}$, while the shorter segments trend ENE-ESE (Fig. 2a).

Domain 2, the Investigator Fault Zone (IFZ), occurs immediately north of domain 1 . The Investigator Fault zone comprises east-west fault segments of the Investigator Fault that intersect the NNE-trending MGFZ, and also comprises seven fault sets (Figs $1 \& 2 b$ ). The dominant rock types in domain 2 are basalts from the Eastern Creek Volcanics, quartzites from the Myally Subgroup, black shales belonging to the McNamara Group and dolerite dykes. Fault orientation occupies the full spectrum of the rose diagram and faults are subvertical (Fig. 2b). The longest faults trend towards the SE and in places form dyke margins. The shortest fault segments trend towards the NE.
Domain 3, the Mammoth Mines region (MM), is north of domain 2 and comprises six fault sets (Figs $1 \& 2 \mathrm{c}$ ). This domain is host to the Gunpowder and Esperanza $\mathrm{Cu}$ ore bodies. This domain comprises east-west fault segments that belong to the Mammoth Extended Fault and Mammoth Fault, as well as NNE-trending segments of the MGFZ. The main rock types within the domain are the same as for domains 1 and 2 (Fig. 1). Here the longest faults trend NNE, while the shortest faults trend NE.

Domain 4 comprises the entire length of the Mount Gordon Fault Zone and has six fault sets (Figs $1 \& 2 d$ ). Several different rock types host the fault zones, mostly Eastern Creek Volcanics and the Myally Subgroup in the west and south, while the McNamaras Group is in the centre of the fault zone. The eastern half of the fault zone is bounded by basalts from the Eastern Creek Volcanics and quartzites from the Myally Subgroup. Even though this overlaps with the other domains, we have considered this as a separate domain because it contains the major structural break of the Mount Gordon Fault (Fig. 1). 


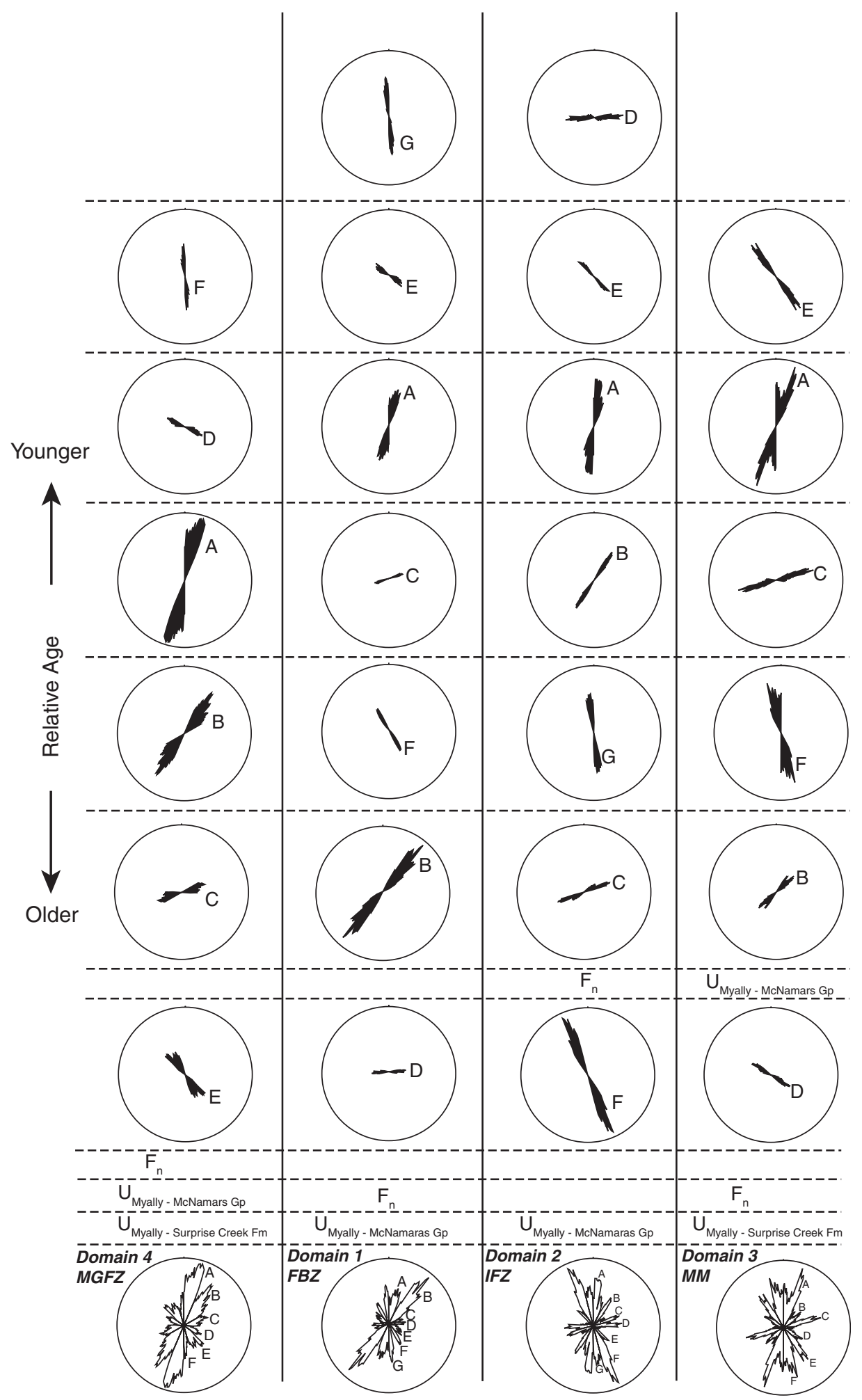

Fig. 7. 


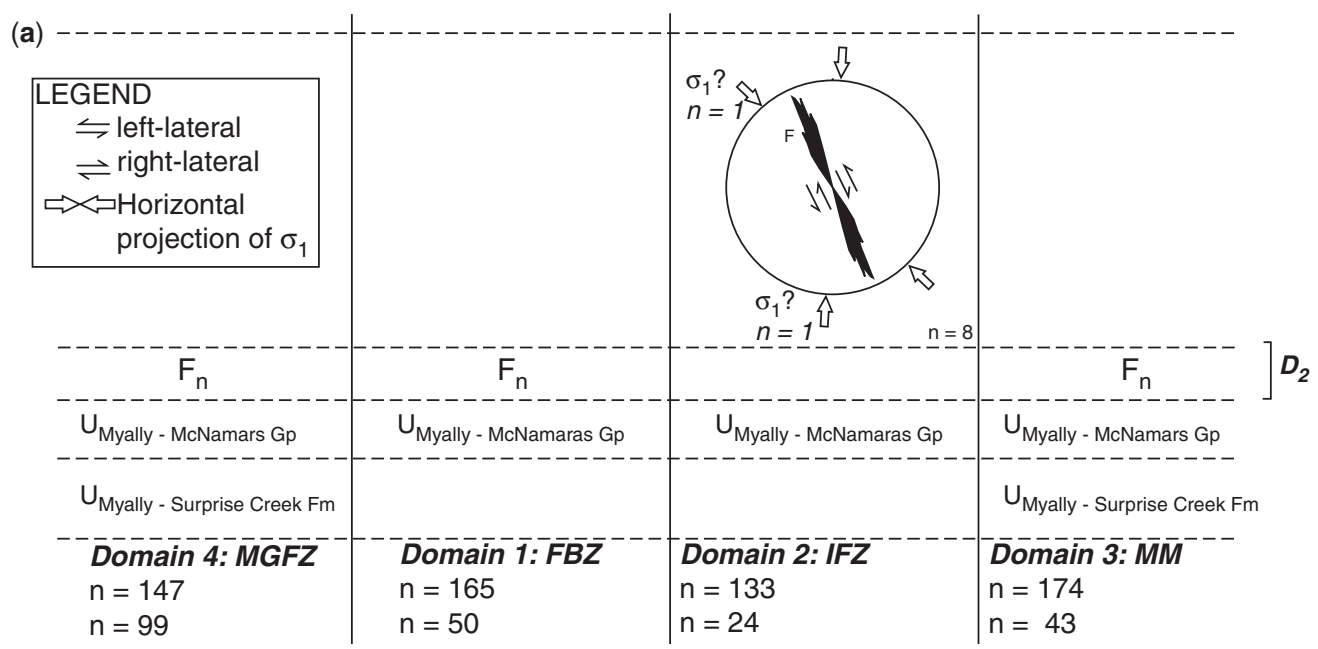

Fig. 8. (a)-(c) Rose diagrams of fault segments showing temporal evolution of the entire fault network within each domain. Columns with domains are plotted according to location with respect to each other; for example, Domain 4 (Mount Gordon Fault Zone) is plotted on the left side of the diagram (i.e. west, because it forms the western boundary of the study area). Refer to Figure 7 for the orientation of all fault segments within each domain and the data points $(n)$. The first $(n)$ is the total amount of faults within the domain and the second $(n)$ represents the faults with an apparent displacement. The horizontal dashed lines represent inferred temporal separation between successive faulting events. The Angelier method was used, along with the methods described in the text, to organize the faults into their age groupings based on overprinting criteria and some geometrical and geological considerations. Correlations between each domain are based on commonality of orientation and relative timing. On each rose diagram plot, a dominant shear sense is coloured black based on the dominant shear sense obtained from mapped relations. The arrows along each side of the rose diagram represent the horizontal trace of $\sigma_{1}$ assuming that there is mostly strike-slip movement along most faults. Black arrows represent high-confidence interpretations. Grey arrows and $\sigma_{1}$ represent a less dominant shear sense inferred from apparent mapped offsets. These grey arrows represent faults with opposing or uncertain shear senses (for which the timing may be wrong for that rose diagram). See also Figure 9.

\section{Geometrical assumptions}

Some simplistic assumptions are required initially. The relationships shown in Figure 3 represent observed geometries of fault bends and intersections in the LRFT. The first assumption is that each orientation of fault or fault segment potentially represents a separate timing of fault activation/reactivation. The likelihood of this being true for all faults on the map is low, particularly for some of the geometries. The simplest geometry of a fault bend (Fig. 3a), for example, could readily form at one time in one faulting event - here, however, we initially assign them to two separate events based on orientation. However, because no overprinting of one segment over the other can be determined, this relationship is assigned a null value in the relative age table (Table 3), so thus can be discriminated (at least by exclusion) from bona fide overprinting faults. The second geometry of the two faults (Fig. 3b) could also occur at one time by faulttip branching, for example; but here we initially assume that the fault that terminates against another fault is older, even though the apparent displacement of the inferred older fault is not seen on the other side of the younger fault. This relationship is assigned a positive value (Fault $\mathrm{X}$ younger than Fault $\mathrm{Y}$ ) in the relative age table but is flagged as a relationship that requires checking in the second phase of analysis. Finally, for relationships in which apparent fault offset is observed, along with the offset of another geological marker (Fig. 3c), the through-going fault most probably is the youngest feature. This relationship is assigned a positive

Fig. 7. Initial relative age analysis rose diagrams where domains $1-4$ have been plotted according to geographical location, along with interpretation where the Myally-Surprise Creek and Myally-McNamaras Group unconformities (i.e. $\mathrm{U}_{\text {Myally-Surprise Creek Fm }}$ ) have been inserted into the analysis. $F_{\mathrm{n}}$ represents observed folding events (all folds are grouped together, i.e. fold generation is not taken into account, $F_{2} \mathrm{v} . F_{4}$ ). Early folded faults were identified geologically rather than via a relative age analysis approach - see Figure 11. North is up on all rose diagrams. 
296

G. S. NORTJE ET AL.

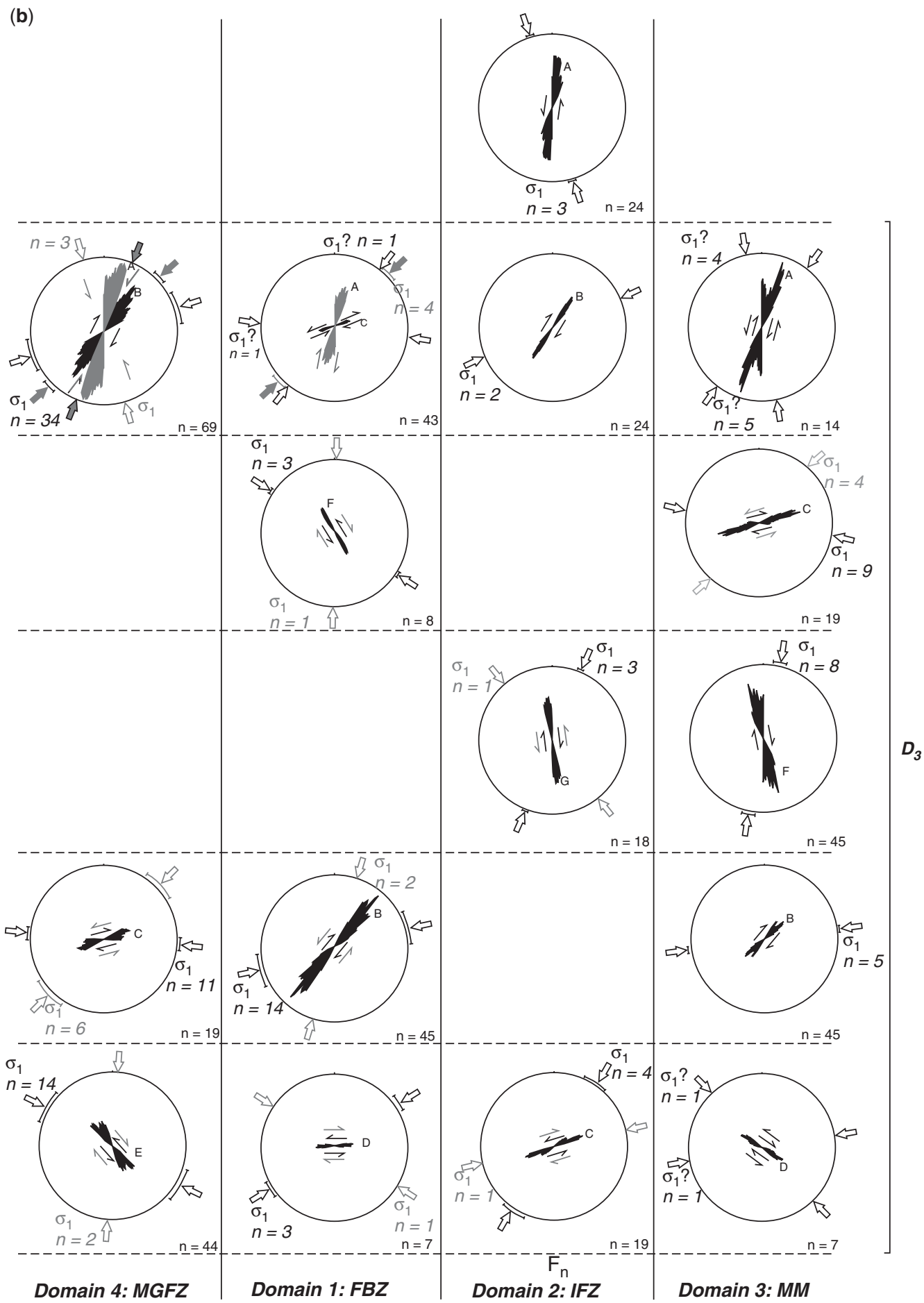

Fig. 8. Continued. 


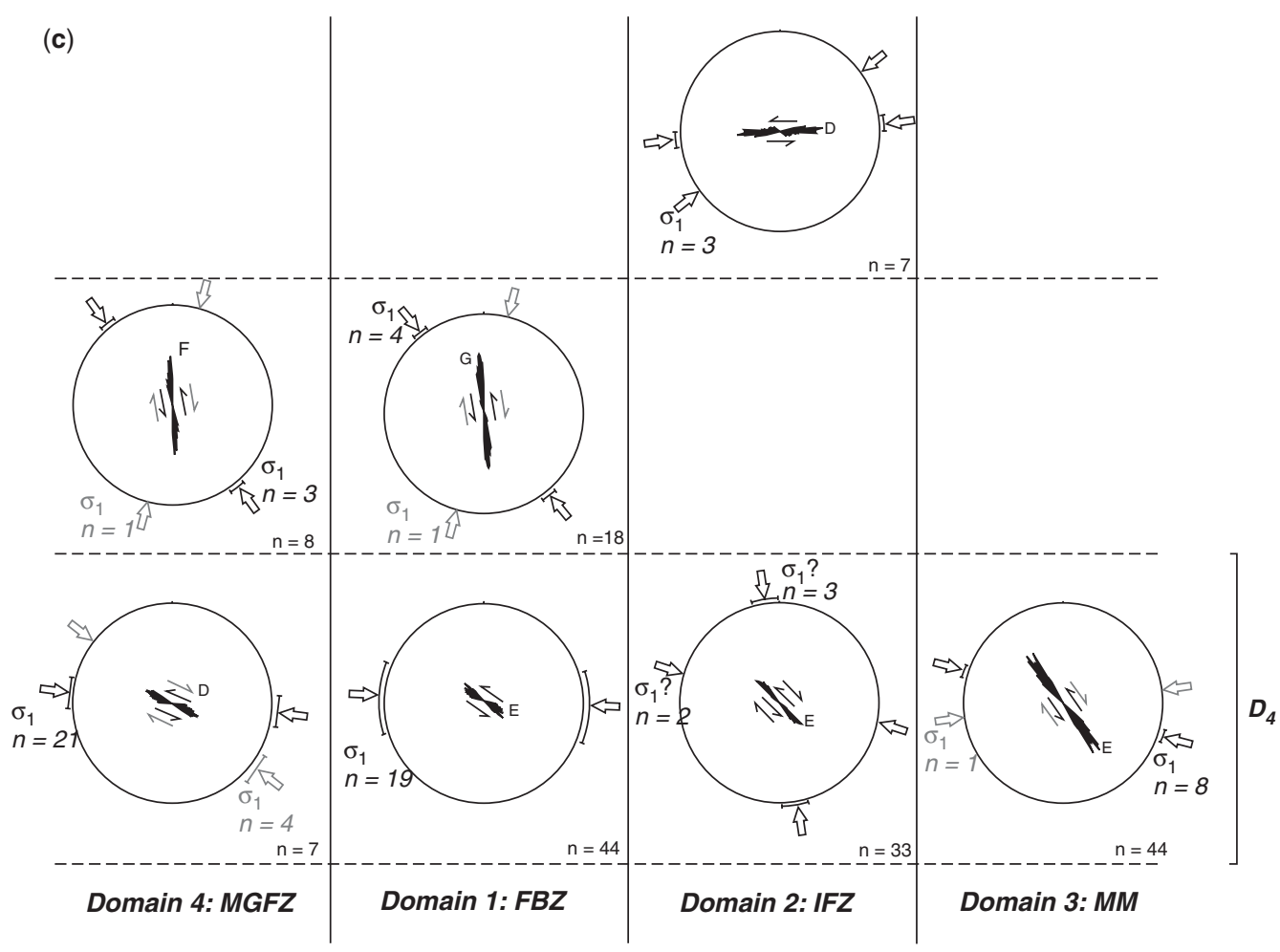

Fig. 8. Continued.

value (Fault $\mathrm{X}$ younger than Fault $\mathrm{Y}$ and the geological feature) with confidence in the relative age table. Because of these exclusions and validity assessments, analysis of these conservative assumptions has the potential to reveal false relationships (such as synchronous fault networks with several orientations).

The relative age table approach is then utilized to try to establish which fault orientations and segments are: (a) consistently; and (b) inconsistently timed relative to each other. For example, for two sets of faults (X and $\mathrm{Y}$ ) with defined orientations, if the number of positive overprinting relationships ( $\mathrm{X}$ younger than $\mathrm{Y}$ ) greatly exceeds both opposite (negative) and null relationships, then it is likely that most faults with orientations of $\mathrm{X}$ formed later than those with orientations of Y. If two sets of faults with nearby orientations consistently show null relationships (e.g. simple fault bends), then it is likely that they formed at the same time. If two sets of faults show a high diversity of positive, negative and null relationships, then there are several possible interpretations but no clear temporal overprinting relationship. This could represent multiple fault events with similar orientations, complex overprinting and reactivation associated with regional stress reorientation, complex conjugate or branching fault relationships for synchronous fault segments, or combinations thereof.

\section{Modification of first interpreted temporal-spatial patterning}

There are several fault orientations that do appear to have consistent enough temporal relationships that a relative chronology can be constructed (Fig. 7). This figure also shows several orientations for which the temporal relationships are inconsistent. The next step involves insertion of known geological events into the constructed chart to try to break the fault groups into the absolute geological history. We inserted Myally-Surprise Creek Formation and Myally-McNamaras Group unconformities, folded faults, as well as faults that offset folds and probably formed during the Isan Orogeny. This reveals four main clusters of fault orientationtime segments (Fig. 7). By consideration of the additional features noted above, we can then assign these fault clusters into pre-Myally, postMyally and pre- $\mathrm{D}_{2}$, and post- $\mathrm{D}_{2}$, etc. (Fig. $8 \mathrm{a}-\mathrm{c}$ ). 
Next, we assessed the extent to which the time-orientation relationships can be modified by identifying single curved faults in which fault segments of different orientation most probably formed contemporaneously. Representative examples include the Investigator Fault, the Mammoth Extended Fault and other unnamed faults throughout the region, particularly in the NE corner of the study area. The Investigator Fault is apparently folded by the $\mathrm{D}_{2}$ event of the Isan Orogeny and truncates dolerite dykes that do not extend into the Mount Isa (McNamaras) Group sediments; both of these features are consistent with this fault being initially developed prior to the Calvert Superbasin sequence sedimentation at 1730-1630 Ma (Gibson \& Henson 2005; Gibson et al. 2008). By assigning the same timing relationships to differently orientated faults along the Investigator Fault (i.e. null), we modified the chart. The same procedure was applied to the other faults where they have clear relationships either with unconformities or folds of known absolute timing. For the Investigator Fault, it could be reasonably assumed that the fault was approximately linear prior to the Isan Orogeny. Thus, several strike orientations between $110^{\circ}$ and $070^{\circ}$ along this fault may represent fault segments that have rotated during folding, as can also be seen with bedding in the area, relative to their original position (Derrick 1982; O'Dea et al. 1997; Gibson \& Henson 2005; Gibson et al. 2008). Furthermore, for this particular fault, the overall symmetry of the fault trace and the folded units and unconformities on the eastern side of the map suggests that it was initially east-west trending. This has also been suggested by other workers
(Derrick 1982; O’Dea et al. 1997; Gibson \& Henson 2005; Gibson et al. 2008).

Following this step, field data (slickenlines, etc.) and the apparent offsets from the regional maps were used for each fault set in each domain to infer an apparent dominant displacement sense, and subordinate displacement sense if the data were inconsistent. From the average orientation(s) and strike-slip movement sense, an inferred $\sigma_{1}$ direction was also calculated. This assumes standard MohrCoulomb rheology and fault-reactivation criterion; that is, $\sigma_{1}$ lies approximately $27^{\circ}$ from the fault plane, which infers a coefficient of friction of 0.72 , and that the initiation of new faults occurs in homogeneous, anisotropic rock, or in the reactivation of optimally orientated faults (Sibson 1985). Figure $8 \mathrm{a}-\mathrm{c}$ shows the inferred temporal evolution and stress field for each of the fault sets within the study area. Black rose diagram segments represent high-confidence interpretations with a consistent shear sense, and grey segments represent opposing or uncertain shear senses. In the latter case, the timing of those particular fault segments may be 'wrong' for that particular rose diagram or some of the faults (either the grey or the black) were reactivated at a later time with a reversed displacement sense. The arrows on the side refer to the corresponding orientation of $\sigma_{1}$ assuming strike-slip movement on steep faults, and the grey shade represents the possible variation of this if the low-confidence faults are considered. By correlation with the literature, we assigned deformation stages on the right, as indicated. The $\mathrm{D}_{4}$ event seems to be consistent and represents the preferred timing of much of the copper in this belt (Miller 2007; Keys 2008).

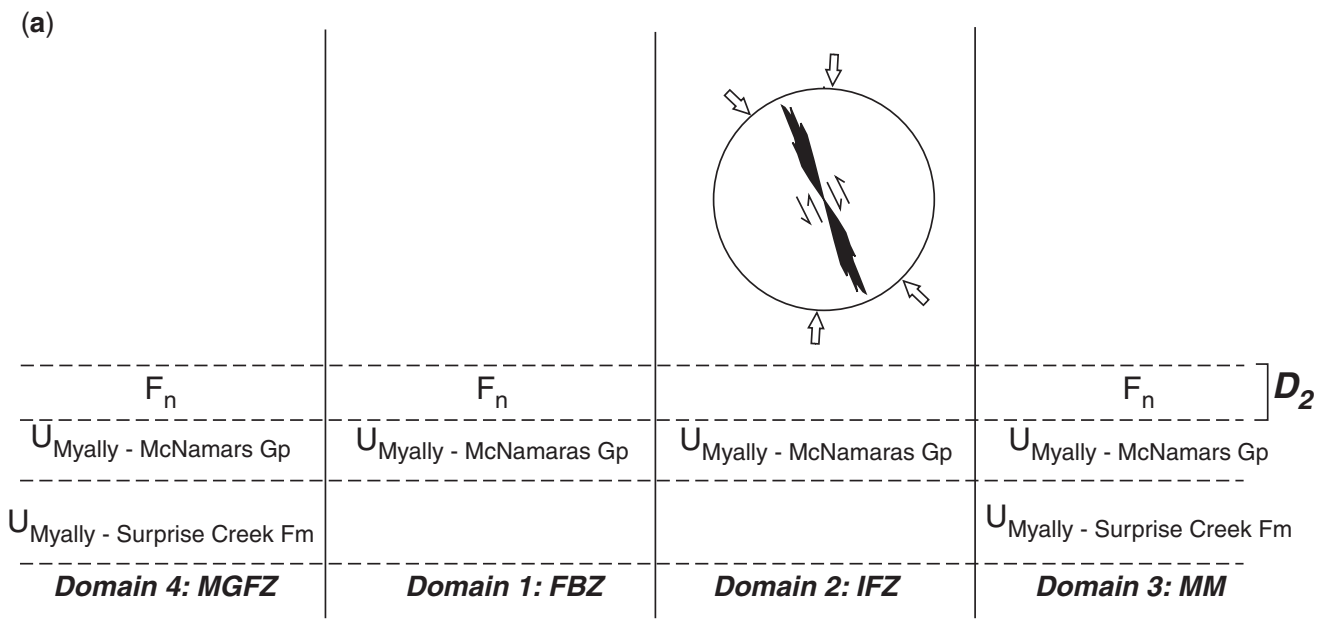

Fig. 9. (a)-(c) Coloured rose diagrams showing temporal evolution of the fault network with dominant trends of $\sigma_{1}$ and shear sense displayed. To be viewed in conjunction with Figure 10. North is up on all rose diagrams. 
(b)

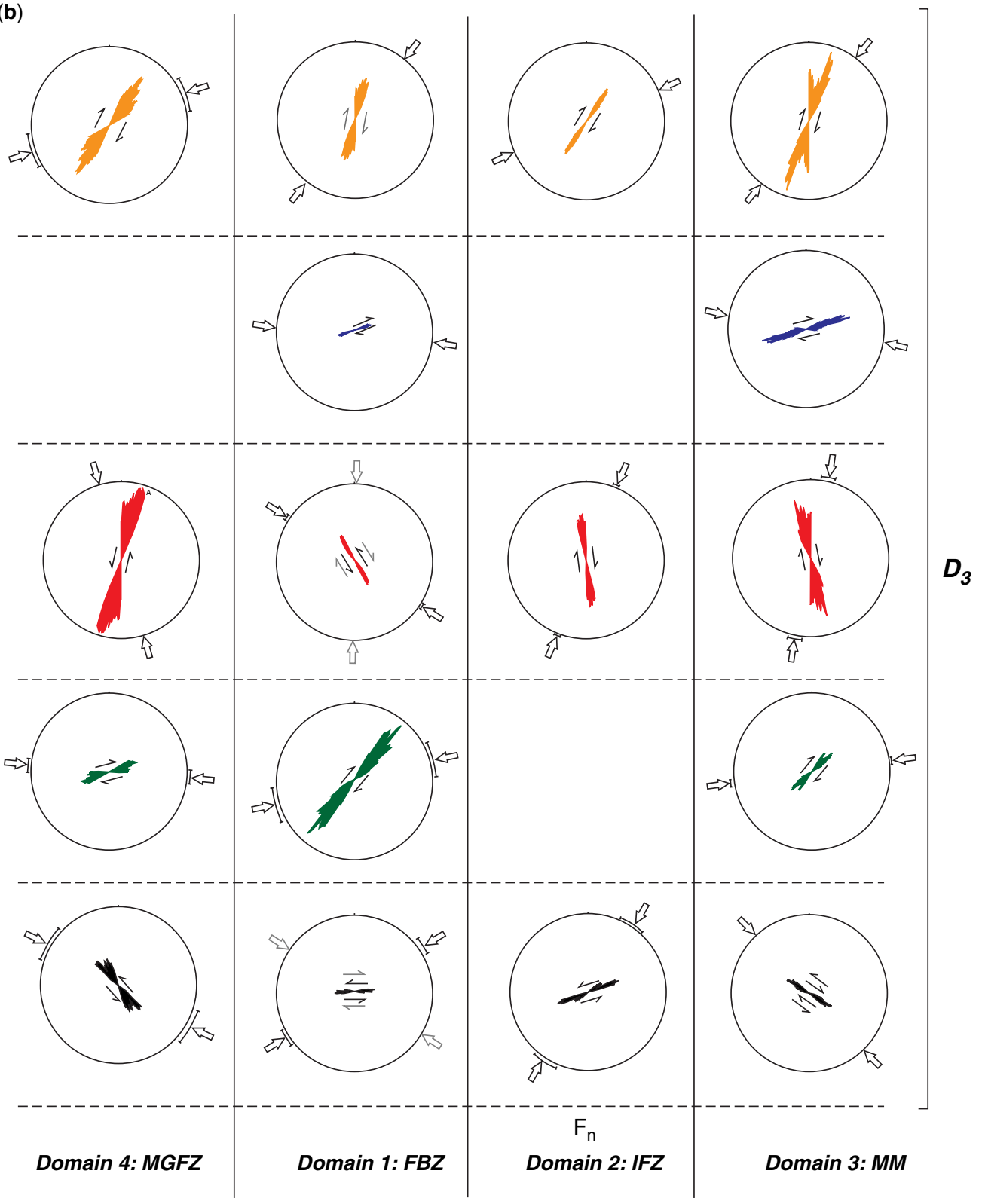

Fig. 9. Continued.

\section{Validity of initial geometrical assumptions}

The geometrical relationships used to infer relative fault timing had variable degrees of reliability, as discussed previously. In particular, the assertion that a shorter fault segment along a ' $\mathrm{Y}$ ' junction is older than a longer segment (Fig. 3) could lead to the erroneous allocation of temporal position if this type of relationship is common. However, this relationship is uncommon on the Mammoth Mines map sheet (Sheet 6758), and there are far more numerous examples where more reliable displacements occur. For example, where faults offset stratigraphy and folds, as well as older faults, or apparent displacements on the map are confirmed with kinematic indicators in the field. Although the ' $Y$ ' junctions could represent fault branches with no distinct timing relationships, the 


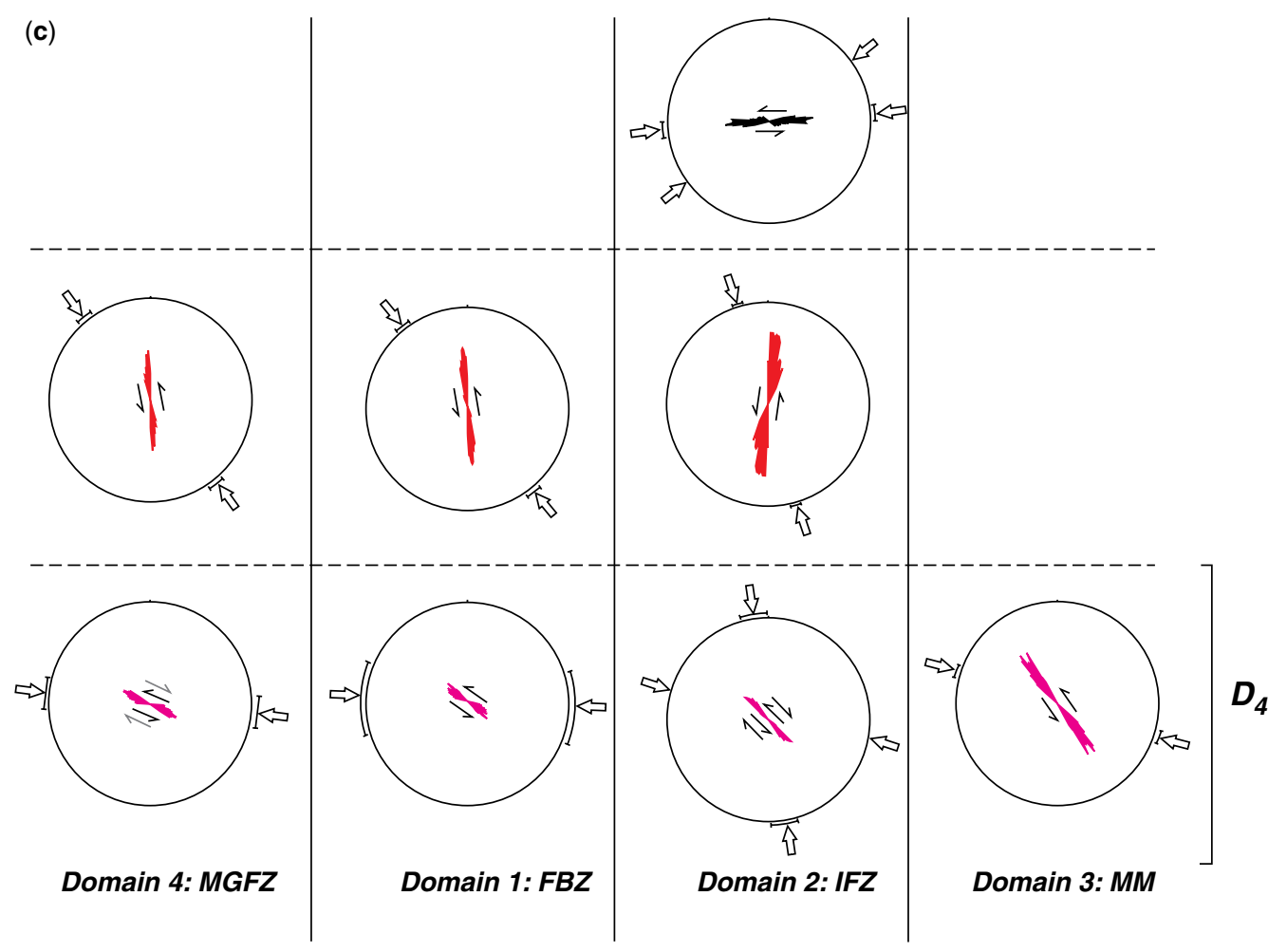

Fig. 9. Continued.

displacement on one side of the fault (without the branch) may have been accommodated parallel to bedding and consequently it has not been mapped. The only way to resolve this is to obtain more field data. However, the overall analysis is not seriously compromised by this assumption (Fig. 3) because of the infrequency of the occurrence of this type of ' $Y$ ' junction and because it is assigned a null value in the relative age analysis if the angle is less than $30^{\circ}$.

\section{Evolution of the MGFZ fault network}

Here we attempt to describe the evolution of the region based on the binary chronological matrix analysis using Figures $9 a-c$ and 10. Figures 9 and 10 display the evolution of the MGFZ fault network in rose diagram form (Fig. 9a-c) and map view showing a schematic evolution of the fault zone (Fig. 10). The evolutionary diagrams can be thought of as a 'fault reactivation' map (Figs $9 \&$ 10). It is apparent from known cross-cutting relationships and field observations that the rock units have been deposited, affected by early faults, then folded and affected by later faults (Figs $1 \& 8 \mathrm{a}-\mathrm{c}$ ). Folding
$\left(F_{n}\right)$ is likely to be related to the peak metamorphic event that affected the whole Mount Isa inlier, $\mathrm{D}_{2}$ (Fig. 8a-c and domains 1-4).

Figures 9a and 10 show that the first fault set that was likely to reactivate was a NW-trending set in the Investigator Fault Zone (IFZ, Domain 2) (Figs 9a \& 10). These faults are may be related to the intrusion of NNW-trending dyke sets that occur to the south and north of the IFZ, Domain 2 (Fig. 10b-d). Field evidence indicates that, at least locally, these dykes have been affected by the Isan Orogeny.

The second set of faults to reactivate was a set of NW (domains 4 and 3) and an east-west and ENE set of faults in domains 1 and 2 (Figs $8 b, 9 b$ \& 10d). The first correlatable fault set to activate/ reactivate(?) are SE- trending faults, with an apparent sinistral shear sense and $\sigma_{1}$ orientated approximately $135^{\circ}-315^{\circ}$ in Domain 4 (MGFZ). A similar set of faults was also reactivated in Domain 3 (Mammoth Mines). In domains 1 and 2, more easterly trending faults were active at this time, with a left-lateral shear sense. Only Domain 3 has a moderately different orientation for $\sigma_{1}$, yet those faults also have a left-lateral shear sense. Faults in domains 4 and 3 have opposite shear 
(a)

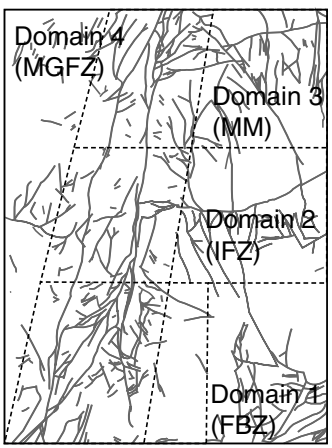

(d)

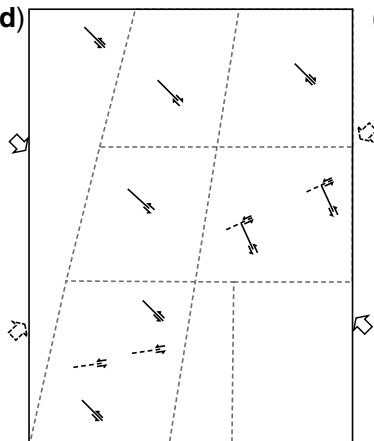

(g)



(j)

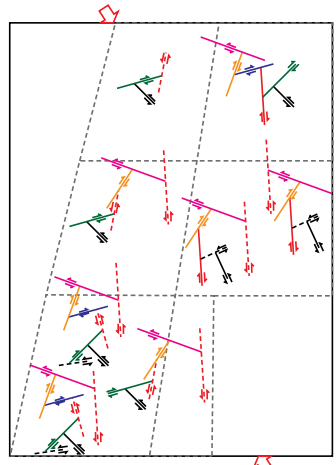

(b)

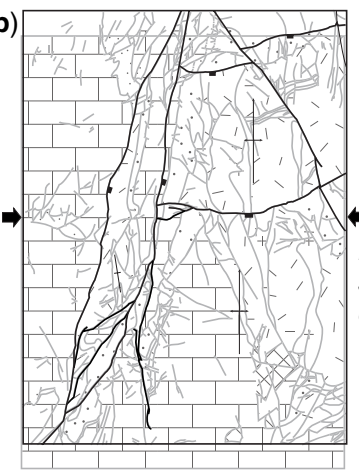

(e)

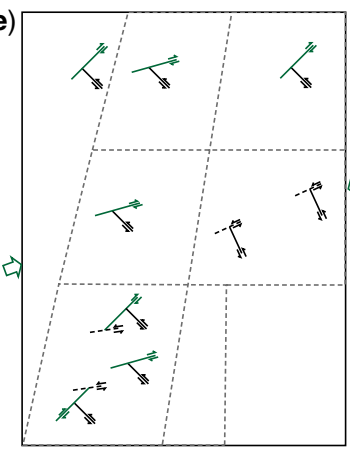

(c)

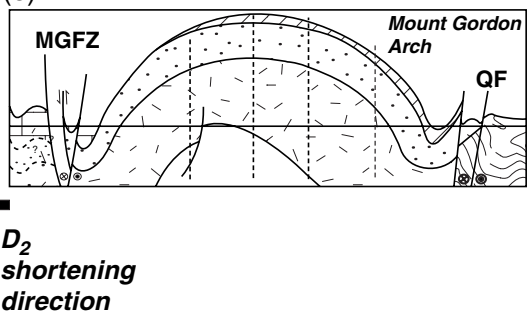

(f)



(h)
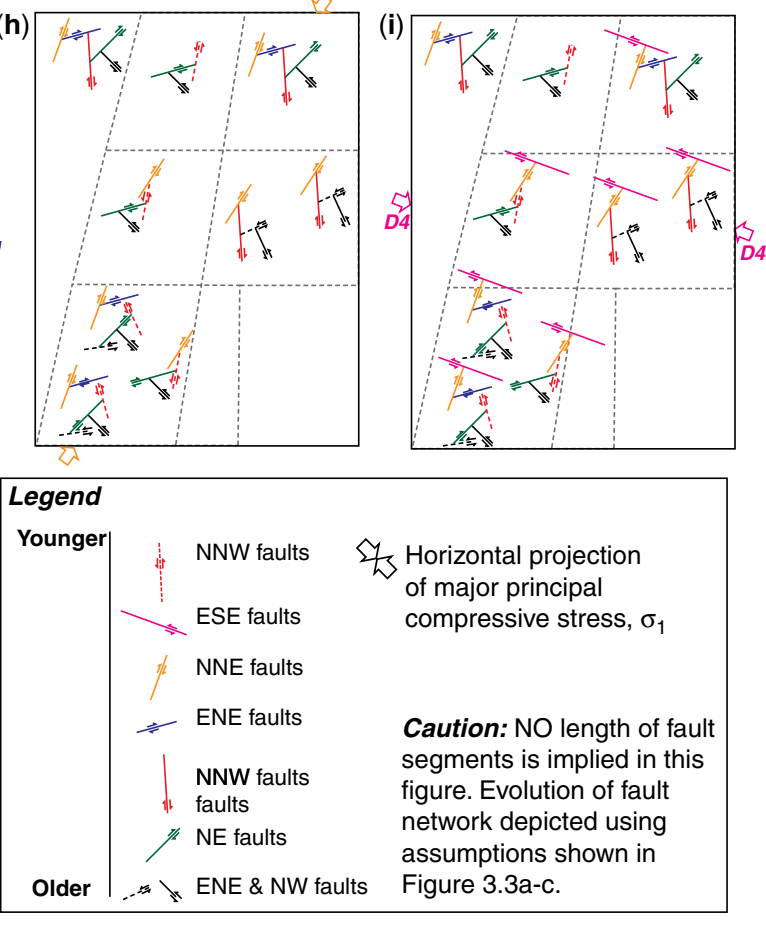

$\beth_{3}$ Horizontal projection of major principal compressive stress, $\sigma_{1}$

Caution: NO length of fault segments is implied in this figure. Evolution of fault network depicted using assumptions shown in Figure 3.3a-c.

Fig. 10. Schematic block diagram showing the evolution of fault network within the study area. (a) Regional fault architecture (not to scale) and domain subdivision. (b) Geological map of the study area showing major normal faults and folding of the Mount Gordon Arch, a pre-Isan Orogeny feature (Derrick 1982; Gibson 2005). The major shortening 
senses with a subparallel $\sigma_{1}$. In domains 1 and 2, the dominant shear sense is left-lateral with a NE-SW $\sigma_{1}$ trend. This set of faults is problematic but, in the binary chronological matrix, the results indicate that they are an early fault set to reactivate or form. They are unresolvable in the sense that there are different orientations of $\sigma_{1}$ and dominant shear senses, so probably reflect more than one stage of faulting.

The next set of faults to develop (reactivate) are a predominantly NE set of faults with a dominant right-lateral shear sense, and a WSW-ENE $\sigma_{1}$ trend in domains 4, 1 and 3 (Figs 8, $9 \& 10 \mathrm{e}$ ).

Within domains 4, 1 and 3, ENE- to NE-trending faults were active with a dominant right-lateral shear sense with an ENE orientation for $\sigma_{1}$ (Figs 8b, 9b \& 10e). Domain 2 (IFZ) does not appear to have any faults active at this time and this may mean that the timing criterion is incorrect or that the domain was not affected by this faulting event and/or deformation may have been taken up by the Investigator Fault.

Faults of the next activation or reactivation event are north-south-trending faults from domains 2 (IFZ) and 3 (MM) (Figs 8, 9 \& 10f), with a dominant right-lateral shear sense and NNE-orientated $\sigma_{1}$. The north-south faults from domains 4 (MGFZ) and 1 (FBZ) are only active at a much later stage in the faulting history. This implies that, at least locally, these north-south faults may have had sufficient cohesion not to reactivate because it is likely that some of these faults are 'old' basin bounding structures and possibly represent old basement faults. It is also apparent that the northsouth faults from domains 4 (MGFZ) and 1 (FBZ) would be in an optimal orientation to reactivate (Sibson 2001), yet they have not (see the Discussion).

In domains 1 and 3 (FBZ and MM) ENE faults are active with a right-lateral shear sense and an ESE-trending $\sigma_{1}$ (Figs $8,9 \& 10 \mathrm{~g}$ ). The final faulting event within the proposed $D_{3}$ event are NNE-trending faults with a dominant right-lateral shear sense from all domains, with a NE-orientated $\sigma_{1}$ (Figs 8-10).

The next faulting event is the inferred $\mathrm{D}_{4}$ coppermineralizing event (McLellan et al. 2006; Miller 2007; Keys 2008). In Figures 8, 9 and 10i the dominant sense of shear is sinistral, with $\sigma_{1}$ orientated approximately $110^{\circ}-120^{\circ}$, thus confirming the propositions of Miller (2007) and Keys (2008) derived by independent methods. Only domains 4 (MGFZ) and 3 (MM) have a minor component of right-lateral shear, with SE- and ENE-orientated $\sigma_{1}$, respectively (Figs 8-10).

The final faulting event affected domains 4 (MGFZ), 1 (FBZ) and 2 (IFZ). Here north-southtrending faults were reactivated with a dominant left-lateral shear sense and a SE-orientated $\sigma_{1}$. It is likely that these faults were reactivated rather than being newly formed because there are north-south faults that were active earlier on in the temporal evolution of faulting (Figs $8 \mathrm{a}-\mathrm{c}, 9 \mathrm{a}-\mathrm{c} \& 10$ ). The alternative is that these faults are newly formed but that implies large differential stresses $\left(\sigma_{1}-\sigma_{3}\right)$ or extremely high pore-fluid pressures with low differential stresses in order to not touch the frictional reshear envelope (see later).

\section{Discussion}

Sibson $(1977,1989,2001)$ proposed that the presence of pre-existing faults in rocks could substantially modify the mechanics and kinematics of propagation of younger faults through the rock mass. 'Old' faults potentially represent zones of low cohesion, damage or soft fault infill that may be reactivated during subsequent deformation events if certain combinations of far-field stress orientations, fluid pressures and fault orientations are met. The generation of new faults in previously

Fig. 10. (Continued) direction during $\mathrm{D}_{2}$ (east-west) in the Isan Orogeny is also shown as it is likely to have folded the Investigator Fault. (c) A generalized cross-section looking north showing the MGFZ in the west and the GeorgeCreek-Quilalar fault system in the east, with the Mount Gordon Arch (Leichhardt anticline), a pre-Isan Orogeny feature modified from Derrick (1982) and Gibson (2005). See Figure 1 for the legend. Modified from Derrick (1982), O'Dea et al. (1997) and Gibson (2005). (d) Development of NW-trending faults, with mostly left-lateral separation and two orientations of $\sigma_{1}$ with two major sets of faults forming. (e) Development of NE-trending faults with mostly right-lateral separation. (f) North-south-orientated faults develop; however, these could also represent reactivated basement structures. (g) Development of ENE-trending faults through the MGFZ (Domain 4) with a dominant right-lateral shear sense. (h) Development of a NE right-lateral fault system during the waning stages of $\mathrm{D}_{3}$, which would agree with the interpretation of the MGF being a $\mathrm{D}_{3}$ structure (Gibson \& Henson 2005). (i) $\mathrm{D}_{4}$ event where copper mineralization occurred along ESE-trending faults with an approximately $110^{\circ} \sigma_{1}$ (Keys 2008). (j) Likely reactivation of NNW-trending faults in a NNW- to NW-orientated stress field, as well as the possible development (reactivation?) of north-south faults within the Fort Binder Fault Zone (FBZ), Domain 1. Arrows outside the boxes represent inferred orientation of stress assuming mostly strike-slip movement along subvertical faults. The length of individual fault segments does not imply that those faults are longer but that they obey our initial assumption (Fig. 3a-c). 
(a)

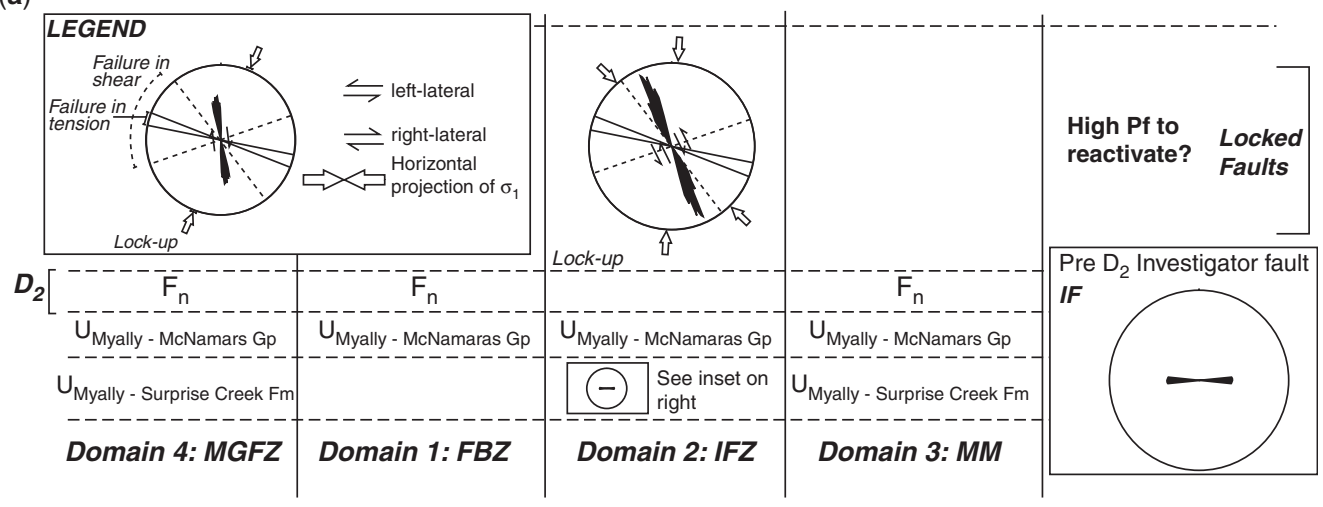

(b)

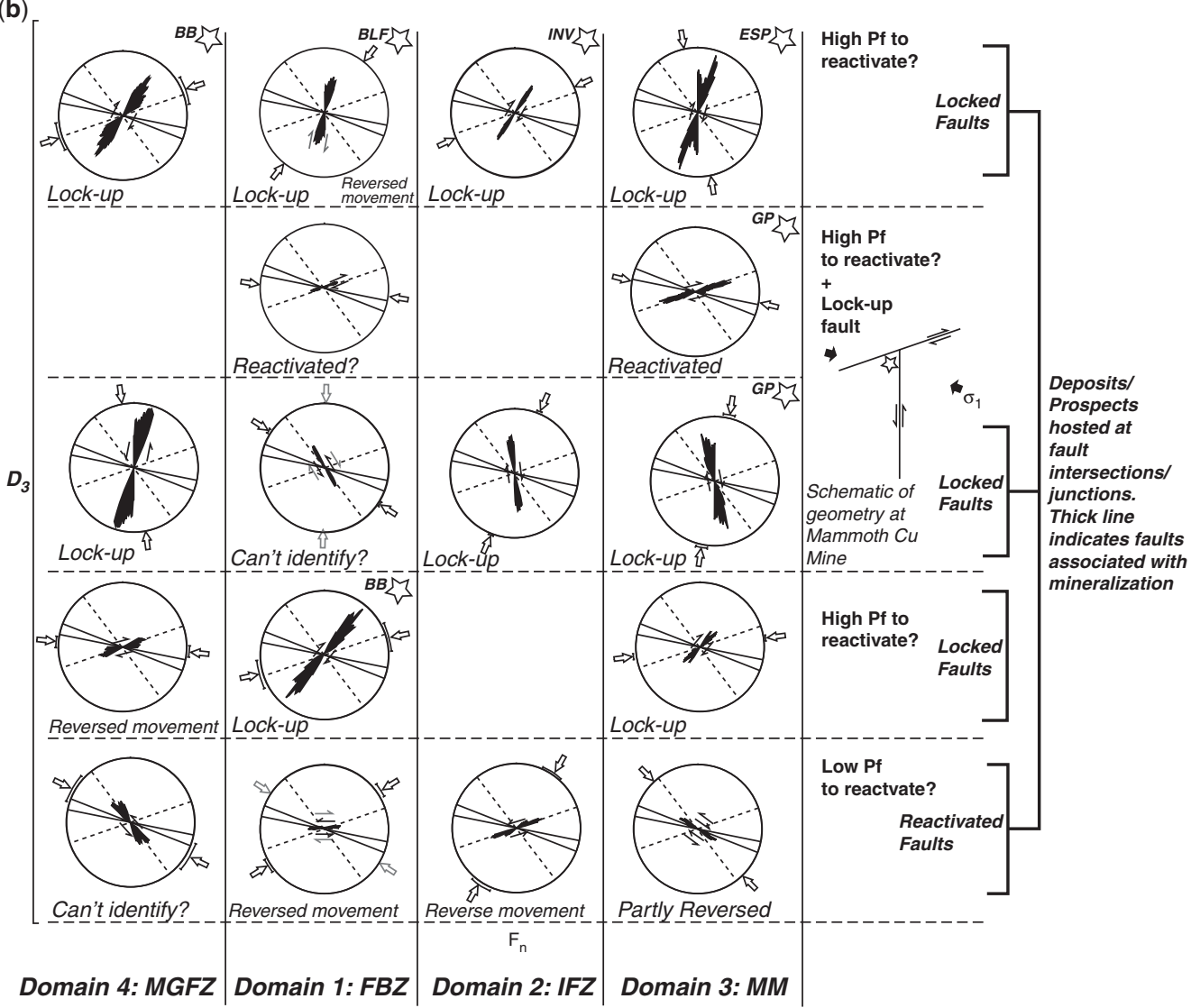

Fig. 11. (a)-(c). Rose diagram plot of the relative chronology of faulting events with an applied $D_{4}$ stress field overlayed on older fault segments. The dominant shear sense and $\sigma_{1}$ orientations are shown. Solid red lines on the overlayed stereonet indicate failure in tension, while blue dashed lines indicate failure in shear according to conventional fault-reactivation analysis techniques (Sibson 1985). The text in each box indicates whether or not the fault set will reactivate under the applied $\mathrm{D}_{4}$ stress field, that is, lock-up, reversed movement sense, reactivated with same shear sense. The far-right column indicates the inferred criterion for fault reactivation to occur and a simplified geometry from the Mammoth Mines region. Stars in the top-right corners of the boxes indicate deposits and prospects on particular faults. Abbreviations as follows: BB, BigBen; BLF, Bluff; INV, Investigator; ESP, Esperanza: GP, Gunpowder. 


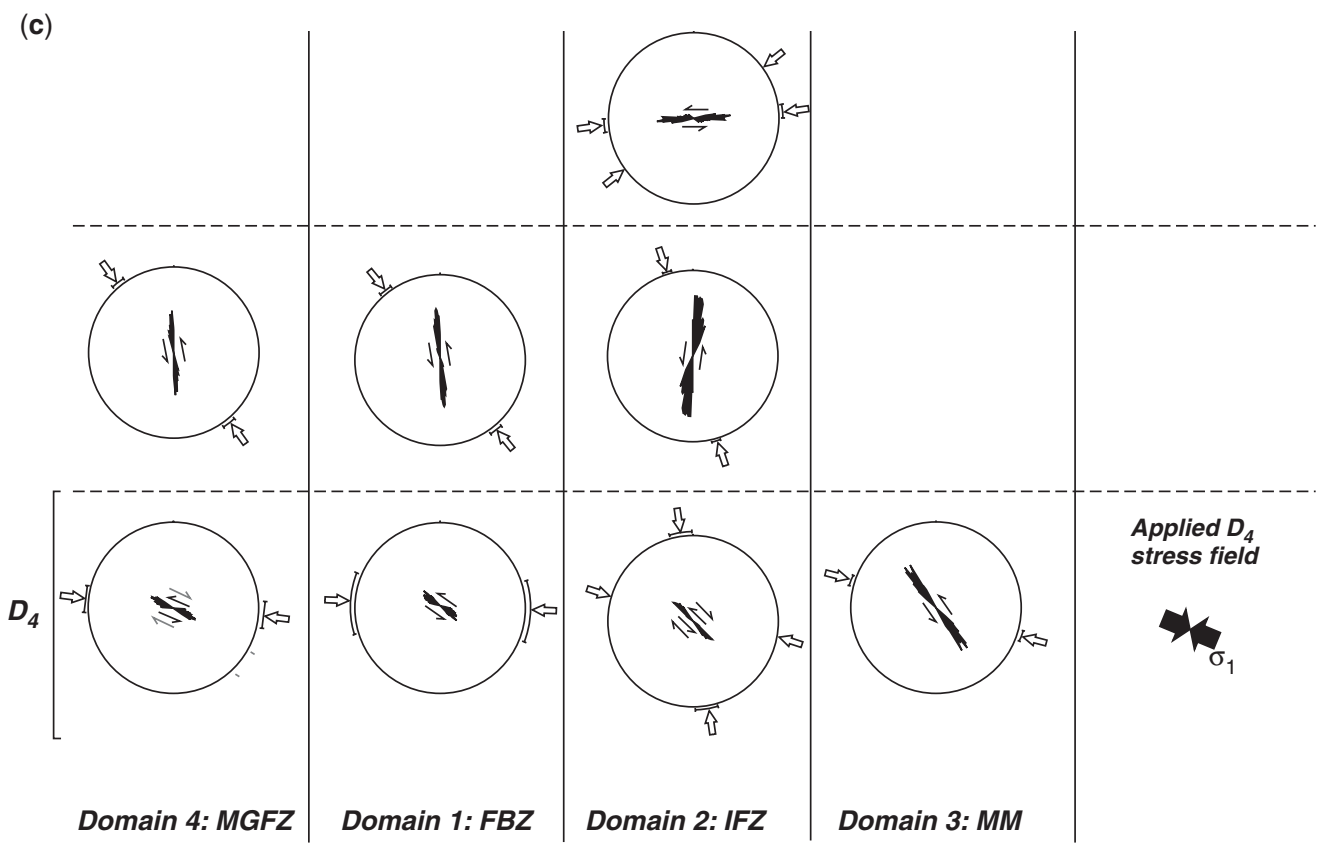

Fig. 11. Continued.

faulted rock masses implies that: (a) the older faults develop cohesion with time, sufficient such that the younger deformation does not 'see' the older faults (Cox et al. 2001); (b) that the far-field stresses associated with the younger deformation are sufficiently misorientated relative to the earlier faults that reactivation is not possible; or (c) that fluid pressures associated with the younger deformation are insufficient for reactivation along the older structures. The features observed in this field area along fault traces range from distinctive quartz 'blows' - veins up to $10 \mathrm{~m}$ wide and $1-200 \mathrm{~m}$ long (which would most likely have high cohesion during subsequent deformation events) - to recessive valleys with poor exposure of rare fault gouge or clay-filled breccia that may have had low cohesion during potential reactivation events.

\section{Conventional fault-reactivation analysis}

Fluid flow leading to mineralization can occur on both newly formed faults and on faults that are reactivated subsequent to their initial formation (Cox et al. 2001; Sibson 2001). Popular models of fault reactivation propose that, under high pore-fluid pressures, misorientated faults may move again due to low fault cohesion (Cox et al. 2001; Sibson 2001). Using the standard criterion for reactivation along faults, a reactivation analysis is shown.
For the main $\mathrm{D}_{4}$ copper-mineralizing event, the greatest principal compressive stress $\left(\sigma_{1}\right)$ was subhorizontally orientated at approximately $110^{\circ}$, with $\sigma_{2}$ subvertical (McLellan et al. 2006; Miller 2007; Keys 2008). For this stress field, faults that strike subparallel to $110^{\circ}$ should have reactivated as dilational fractures possibly with breccias, and faults whose orientation is between approximately $27^{\circ}$ and $54^{\circ}$ from $\sigma_{1}$ should have been optimally orientated for shear failure (Sibson 1986, 1996, 2000, 2001). Figure 11 shows this imposed $\mathrm{D}_{4}$ stress field for faults that are older than the $\mathrm{D}_{4}$ faults.

The far right column in Figure 11 describes whether or not faults could reactivate in tension (faults lying between the red lines), shear (faults lying in the acute angle between the blue dashed lines) or may not have reactivated due to their high angle to $\sigma_{1}$ (faults lying outside the blue dashed lines). Faults have been labelled either as 'locked faults' or 'reactivated faults', based on the theoretical orientation analysis of reactivation just described. For locked faults to reactivate they would require high pore-fluid pressure, while optimally orientated faults should reactivate either in shear or tension, potentially with lower pore-fluid pressures (Fig. 11).

It is apparent from Figure 11 that many of the older faults from all four domains should have 
reactivated under a $\mathrm{D}_{4}$ stress field in tension or in shear, but many did not. Figure 11 shows the youngest event $\mathrm{D}_{4}(\mathrm{ESE}-\mathrm{WNW})$, for which the inferred stress field is applied to all older faults to check their potential for reactivation in tension and shear (Figs 12-14). Figure 12 shows late $D_{3}$ faults (Fig. 11) with the applied $\mathrm{D}_{4}$ stress field. Late $\mathrm{D}_{3}$ faults host mineralization (Fig. 12) yet they are all severely misorientated for reactivation, which implies that they required sufficiently high porefluid pressures and low cohesion to reactivate under a $\mathrm{D}_{4}$ stress field. The existence of the $\mathrm{D}_{4}$ faults, however, seems to require that, at some point, the late $\mathrm{D}_{3}$ faults did not reactivate, but that new faults formed instead, implying a change either in pore-fluid pressure conditions or in cohesion of the late $\mathrm{D}_{3}$ faults after they formed (see below).

Figure 13 shows mid- $\mathrm{D}_{3}$ faults under the applied $\mathrm{D}_{4}$ stress regime. While these faults do not host economic grades of mineralization, other than the Mammoth Mines domain, these faults would also have required high pore-fluid pressure to reactivate, along with low cohesion.

Figure 14 depicts early $D_{3}$ faults under the applied $\mathrm{D}_{4}$ stress regime. These faults should have reactivated in shear and/or tension, but apparently did not (no shear-sense reversal or tensile veins on the fault). This is likely due to these faults having either a high cohesion during reactivation and/or low pore-fluid pressure (Fig. 14).

For the formation of new faults under $\mathrm{a}_{4}$ stress field (Fig. 11), it is likely that high differential stresses would be needed. The simple observation that many different fault orientations exist, with an apparent consistency of relative timing relationships, requires that new faults commonly developed in rocks that already contained older faults. Thus, the majority of the older faults would have had to have sufficiently high cohesion so as not to 'see' the younger deformation (Cox et al. 2001), unless pore-fluid pressures were quite low during the younger events. However, the occurrence of dilational hydrothermal mineralization on some young faults would appear to be evidence that high porefluid pressures were locally attained and faults were reactivated in tension.

\section{Exploration implications}

Deposits and prospects commonly lie at the intersection between faults of differing ages and orientations; however, this analysis does not specifically include the fault intersections for consideration. For example, the Mammoth copper ore body is located at an intersection between ENEand north-south-trending faults (mid- $\mathrm{D}_{3}$ faults) (Figs $11 \& 13$ ). A possible model for the formation of this deposit is that the north-south fault locked up owing to its severe misorientation under an applied $\mathrm{D}_{4}$ ESE stress field. The ENE-trending fault may have reactivated in shear mode, as suggested by field relationships and by quartz textures in the fault fill (Nortje 2009). This reactivated fault may have acted as a fluid conduit during reactivation, providing a source of copper-bearing fluids, further facilitated by the fairly large size of this fault (with potential connections to diverse copper sources). The 'locking' of a fault during a regional reactivation event can lead to increases in pore-fluid pressure, prior to a potential large earthquake event when slip finally occurs (Sibson 1977 , 1989, 2001; Cox et al. 2001). If such a locked fault is connected to a fault that is being successfully reactivated along at least some of its length, then the latter fault could act as a conduit for fluids to be directed towards the locked fault, depending on the overall geometrical configuration. Thus, at the point where the two faults meet, a zone of particularly high pore-fluid pressure may develop that would accentuate the potential for eventual catastrophic failure localization at the junction. This may also be assisted by local perturbations of the stress field at the junction. The location of mineralized breccia at the Mammoth deposit is considered to reflect this type of fault interaction; palaeostress modelling at that junction also suggests anomalously high pore-fluid pressures on one side of the junction coupled with an anomalous stress field (Fig. 15) (Keys et al. 2006).

A regionally testable hypothesis is that lowcohesion faults are recessive, with clays and damage zones dominating the fault fill; that is, predominantly north-south-trending faults. Faults that trend ESE-SE, or east-west, containing protruding fault fill of coarse quartz, brecciated quartz and fibrous quartz were likely to be highly cohesive faults. Faults with high cohesion may have acted as barriers and compartments, so that intersections between them and newly formed faults provided exploration targets, not because of reactivation but because of the interaction between new faults and the cohesive materials defined either by fault precipitates or by rock juxtaposition (Fig. 16).

\section{Conclusions}

- The relative age analysis method (binary chronological matrix analysis) has been shown to be a valid tool to use in the study of the evolution of a Proterozoic mineralized and faulted terrain.

- Further evidence for $\mathrm{D}_{4}$ being the main coppermineralizing event, as proposed elsewhere at the Mount Isa, Mammoth and Mount Kelly $\mathrm{Cu}$ 


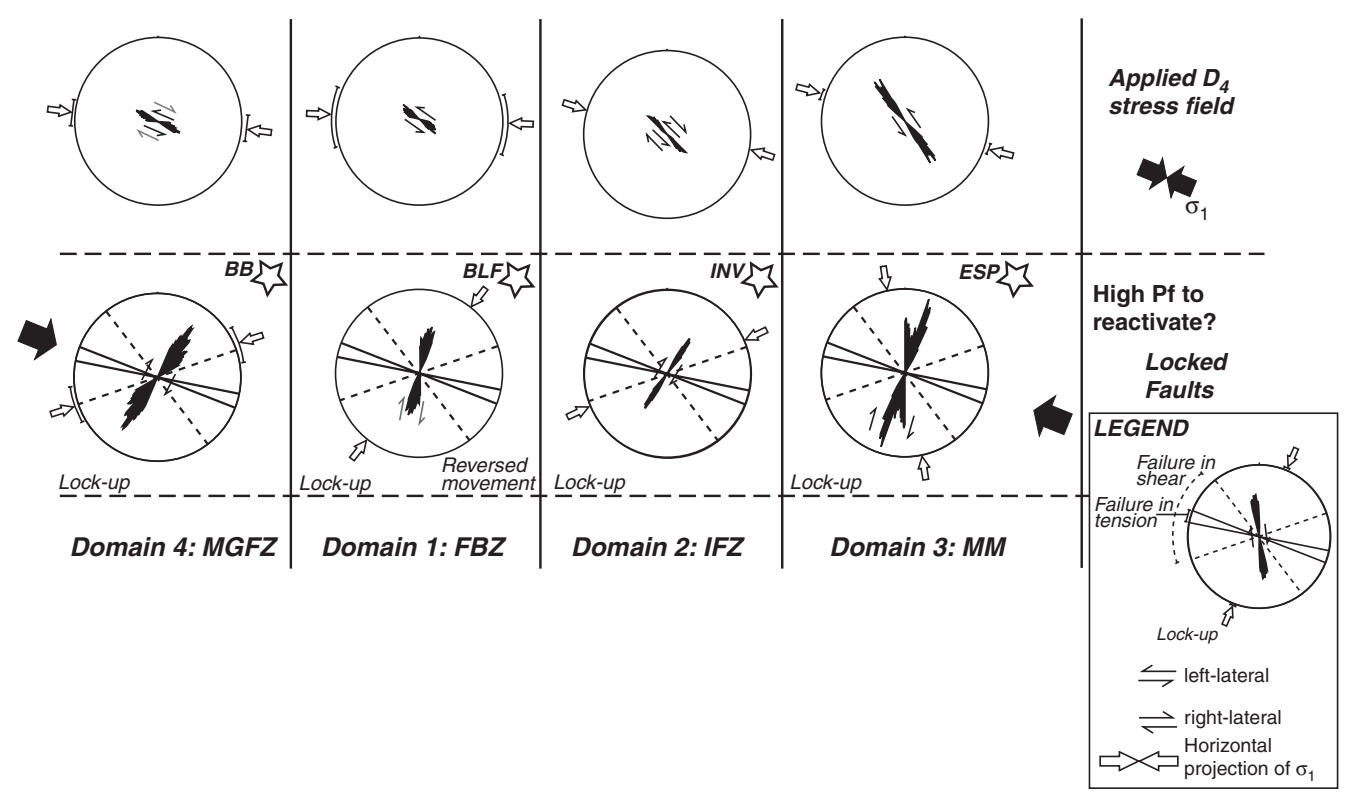

Fig. 12. $D_{4}$ stress field applied to late $D_{3}$ faults, and these faults are mineralized during $D_{4}$ and are in 'lock up' orientation under $\mathrm{a}_{4}$ stress field. These faults are likely to have had low cohesion and required high pore-fluid pressure to reactivate in tension. Solid red lines on the overlayed stereonet indicate potential reactivation by failure in tension, while blue dashed lines indicate reactivation in shear according to conventional fault- reactivation analysis techniques (Sibson 1985).



Fig. 13. Mid- $D_{3}$ faults under a $D_{4}$ stress field. These faults are in 'lock up' orientation with little no or no mineralization, with one exception (Gunpowder). These faults probably had insufficient pore-fluid pressure for reactivation on low-cohesion faults. Solid red lines on the overlayed stereonet indicate reactivation potential for failure in tension, while blue dashed lines indicate potential failure in shear according to conventional fault-reactivation analysis techniques (Sibson 1985). 




Fig. 14. Early- $D_{3}$ faults under $a D_{4}$ stress field. These faults are in a good orientation to reactivate but apparently did not reactivate, and several younger generations of faults cut these faults. It is likely that these faults had high cohesion during the attempted reactivation. Solid red lines on the overlayed stereonet indicate failure in tension, while blue dashed lines indicate failure in shear according to conventional fault-reactivation analysis techniques (Sibson 1985).

deposits, is independently verified here for the study area.

- The temporal evolution of faults within the region, with new faults forming in rocks that already contained faults, requires that many older faults developed sufficient cohesion that they did not subsequently reactivate, even in favourable orientations for reactivation. In contrast, at certain locations, fault reactivation in tension, at high pore-fluid pressures, produced breccias and mineralization.

- Faults with high cohesion may have acted as barriers and compartments, so that intersections between them and newly formed faults provided exploration targets, not because of reactivation but because of the interaction between new faults and the cohesive materials defined either by fault precipitates or rock juxtaposition.

- The general assumption that older faults generally have low cohesion is not borne out by this study. Rather, this study points towards the need to recognize the potential for high-cohesion old faults, as these may be places where porefluid pressure was forced upwards. The faults did not reactivate but, rather, the combination of high fluid pressures and fault 'locking' permitted brecciation and focused fluid flow, leading to mineralization.

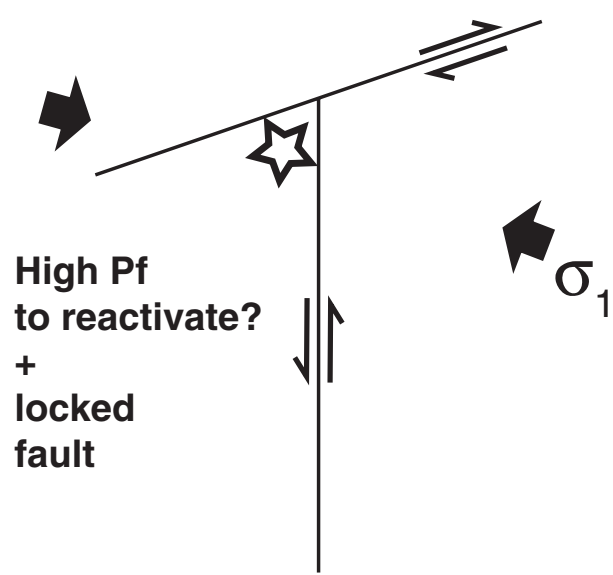

Fig. 15. Simplified model for the formation of the Mammoth Mines (Gunpowder) and deposits/prospects in the general in the study area. Under an applied $D_{4}$ ESE stress field, the old north-south fault locks, while the ENE-trending fault reactivates in shear. The north-south fault facilitates the build up of high pore-fluid pressures, while the ENE-trending fault behaves like a fluid conduit where fluid focusing occurs at the intersection of the two faults, resulting in mineralization. 


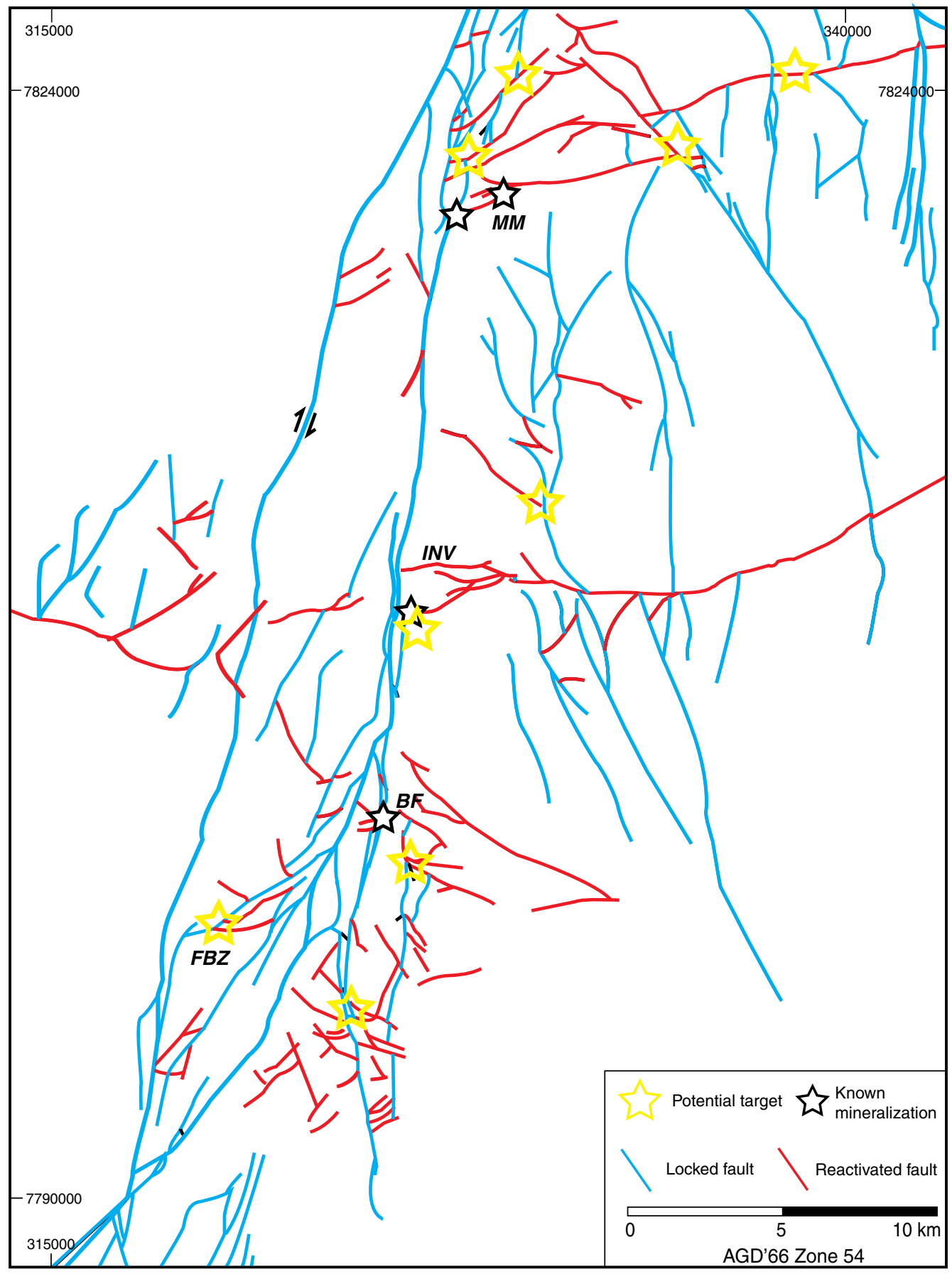

Fig. 16. Fault map of locked (recessive faults - blue) and reactivated (protruding faults - red) faults based on an applied $\mathrm{D}_{4}$ stress field (Figs 11-14). Locked faults (blue) are known to be recessive but some are predicted to be recessive using this method. The white stars show known mineralization and the yellow stars show potential targets. Map projection AGD 1966 zone 54. 
This work was supported by the Predictive Mineral Discovery Cooperative Research Centre (pmd*CRC). We thank AdityaBirla Ltd, CopperCo Ltd, and Xstrata Copper (Mount Isa) for providing invaluable assistance while G. S. Nortje and D. L. Keys undertook fieldwork. G. S. Nortje and D. L. Keys were awarded $p m d^{*} C R C$ top-up scholarships. G. S. Nortje thanks G. Dryden and D. Brigden of SunWater Ltd for providing the necessary assistance to his complete postgraduate study. We thank D. Healy, J. Kolb and A. Fagereng (editor) for insightful and constructive reviews that greatly improved the clarity of the manuscript.

\section{References}

Angelier, J. 1991. Analyse chronologique matricielle et succession régionale des événments tectoniques. Comptes Rendu de l'Academie des Sciences Paris, 312, 1633-1638.

Angelier, J. 1992. CHRONO, 1.07, Paris, France.

Angelier, J. 1994. Fault Slip Analysis and Palaeostress Reconstruction. In: HANCOCK, P. L. (ed.) Continental Deformation. Pergamon Press, New York, 421.

BeLl, T. H. 1983. Thrusting and duplex formation at Mount Isa. Nature, 304, 493-497.

BELL, T. H. 1991. The role of thrusting in the structural development of the Mount Isa Mine and its relevance to exploration in the surrounding region. Economic Geology, 86, 1602-1625.

Bell, T. H., Perkins, W. G. \& Swager, C. P. 1988. Structural controls on development and localization of syntectonic copper mineralization at Mount Isa, Queensland. Economic Geology and the Bulletin of the Society of Economic Geologists, 83, 69-85.

BetTs, P. 2000. Asymmetric extension of the lithosphere and its influence on Palaeoproterozoic $\mathrm{Pb}-\mathrm{Zn}$ deposits of the Western fold belt, Mount Isa Terrane. Journal of the Virtual Explorer, 1, 28-42.

Betts, P. G. 1999. Palaeoproterozoic mid-basin inversion in the northern Mt. Isa terrane, Queensland. Australian Journal of Earth Sciences, 46, 735-748.

Betts, P. G., Giles, D. \& Lister, G. S. 2003. Tectonic environment of shale-hosted massive sulfide $\mathrm{Pb}-\mathrm{Zn}-\mathrm{Ag}$ deposits of Proterozoic northeastern Australia. Economic Geology and the Bulletin of the Society of Economic Geologists, 98, 557-576.

Blake, D. H. 1987. Geology of the Mount Isa Inlier and environs, Queensland and Northern Territory. Canberra, Bureau of Mineral Resources Bulletin, 225, 83.

Blake, D. H. \& Stewart, A. J. 1992. Stratigraphic and tectonic framework, Mount Isa Inlier. In: STEwart, A. J. \& Blake, D. H (eds) Detailed Studies of the Mount Isa Inlier. Australian Geological Survey Organisation Bulletin, Canberra, 243, 1-11.

Cox, S. F., Knackstedt, M. A. \& Brawn, J. 2001. Principles of structural control on permeability and fluid flow in hydrothermal systems. In: RICHARDS, J. P. \& Tosdal, R. M. (eds) Structural Controls on Ore Genesis. Reviews in Economic Geology 14. Society of Economic Geologists, Littleton, CO, 1-22.

Davis, T. P. 2004. Mine-scale structural controls on the Mount $\mathrm{Isa} \mathrm{Zn}-\mathrm{Pb}-\mathrm{Ag}$ and $\mathrm{Cu}$ orebodies. Economic
Geology and the Bulletin of the Society of Economic Geologists, 99, 543-559.

Derrick, G. M. 1982. A Proterozoic rift zone at Mount Isa, Queensland, and implications for mineralization. BMR Journal of Australian Geology and Geophysics, 7, 81-92.

Duncan, R., Hitzmann, M., Nelson, E., Stein, H., Zimmerman, A. \& Kirwin, D. 2009. Re-Os Molybdenite Ages for the Southern Cloncurry IOCG District, Queensland, Australia: Protracted Mineralisation Over 210 myr. In: Williams, P. J. (ed.) Smart Science for Exploration and Mining, Volume 2: Townsville, QLD, Australia. Economic Geology Research Unit and Society for Geology Applied to Mineral Deposits, Townsville, 626-628.

Etheridge, M. A., Rutland, R. W. R. \& Wyborn, L. 1987. Orogenesis and tectonic process in the early to Middle Proterozoic of northern Australia. In: KRÖNer, A. (ed.) Precambrian Lithospheric Evolution. American Geophysical Union, Geodynamic Serial 17, 131-147.

Forster, M. A. \& Lister, G. S. 2008. Tectonic sequence diagrams and the structural evolution of schists and gneisses in multiply deformed terranes. Journal of the Geological Society, 165, 923-939.

GiBson, G. M. 2005. Chapter 3: Chronostratigraphy and geodynamic evolution of the Western Succession. In: Gibson, G. M. \& Hitchman, A. P (eds) Project I 1: $3 D$ Basin Architecture \& Mineral Systems in the Mt Isa Western Succession. Predictive Mineral Discovery Cooperative Research Centre, Canberra, 31-82.

Gibson, G. M. \& Henson, P. A. 2005. Chapter 6: Postdepositional deformation in the Western Succession. In: Gibson, G. M. \& Hitchman, A. P. (eds) Project I 1: $3 D$ Basin Architecture \& Mineral Systems in the Mt Isa Western Succession. Predictive Mineral Discovery Cooperative Research Centre, Canberra, 147-176.

Gibson, G. M., Rubenach, M. J., Neumann, N. L., Southgate, P. N. \& Hutton, L. J. 2008. Syn- and post-extensional tectonic activity in the Palaeoproterozoic sequences of Broken Hill and Mount Isa and its bearing on reconstructions of Rodinia. Precambrian Research, 166, 350-369.

Gregory, M., Schafer, B., Keays, R. \& Wilde, A. 2008. Rhenium-osmium systematic of the Mt Isa copper ore body and the Eastern Creek Volcanics, Queensland, Australia: implications for ore genesis. Mineralium Deposita, 43, 553-573.

Heinrich, C. A. \& Cousens, D. R. 1989. Semiquantitative electron microprobe analysis of fluid inclusion salts from the Mount Isa copper deposit (Queensland, Australia). Geochimica et Cosmochimica Acta, 53, 21-28.

Heinrich, C. A., Bain, J. H. C., Memagh, T. P., Wyborn, L. A. I., ANDrew, A. S. \& WARING, C. L. 1995. Fluid and mass transfer during metabasalt alteration and copper mineralization at Mount Isa, Australia. Economic Geology, 90, 705-730.

Holyland, P. W. \& Ojala, V. J. 1997. Computer-aided structural targeting in mineral exploration: two- and three-dimensional stress mapping. Australian Journal of Earth Sciences, 44, 421-432. 
Hutton, L. J., Derrick, G. M. \& Gallagher, J. 1985. Geology of the Mammoth Mines Region 1:100 000, Geological Series Sheet 6758. Australia, Bureau of Mineral Resources, Canberra.

Keys, D. L. 2008. Mechanical localisation of copper deposits in the Mt Isa Inlier. North Queensland. Unpublished $\mathrm{PhD}$ thesis, James Cook University, 338p.

Keys, D. L., Oliver, N. H. S. \& Mclellan, J. G. 2006. Resolving the structural setting of the Gunpowder copper deposits, using numerical modelling. North Queensland GSA 18th Australian Geological Convention, Melbourne, 2006.

Kolb, J., Rogers, A., Meyer, F. M. \& Vennemann, T. W. 2004. Development of fluid conduits in the auriferous shear zones of the Hutti Gold Mine, India: evidence for spatially and temporally heterogeneous fluid flow. Tectonophysics, 378, 65-84.

Lister, G. S., O'Dea, M. G. \& Somaia, I. 1999. A tale of two synclines; rifting, inversion and transpressional popouts at Lake Julius, northwestern Mt. Isa Terrane, Queensland. Australian Journal of Earth Sciences, 46, 233-250.

Lister, G. S., Thomas, A. \& DunN, J. 1986. Tectonic processes in the Mount Isa Inlier; the significance of transpressional strike-slip faulting. In: BRANCH, C. D (ed.) Eighth Australian Geological Convention; Geological Society of Australia; Earth Resources in Time and Space. Geological Society of Australia, Adelaide, 15, 127-128.

Lister, G. S., Thomas, A. D., Dunn, J. 1987. The significance of transpressional strike-slip faulting in the Lake Julius area, Mount Isa Inlier. In: ANONYMOUS (ed.) International Conference on Deformation of Crustal Rocks. Geological Society of Australia, Mt Buffalo, 19, 39-40.

Mair, J. L., OJala, V. J., Salier, B. P., Groves, D. I. \& Brown, S. M. 2000. Application of stress mapping in cross-section to understanding ore geometry, predicting ore zones and development of drilling strategies. Australian Journal of Earth Sciences, 47, 895-912.

McLellan, J. G. \& Oliver, N. H. S. 2008. Discrete element modelling applied to mineral prospectivity analysis in the eastern Mount Isa Inlier. Precambrian Research, 163, 174-188.

Mclellan, J. G., Oliver, N. H. S. \& Hobbs, B. E. 2006. The relative effects of deformation and thermal advection on fluid pathways in basin-related mineralization. Journal of Geochemical Exploration, 89, 217-275.

Micklethwaite, S., Sheldon, H. A. \& Baker, T. 2010. Active fault and shear processes and their implications for mineral deposit formation and discovery. Journal of Structural Geology, 32, 151-165.

MiLler, J. McL. 2007. Structural controls on the Mt Isa Copper deposit, QLD, Project I7, Predictive Mineral Discovery CoOperative Research Centre, 70.

Neumann, N. L., Southgate, P. N., Gibson, G. M. \& McInTYRe, A. 2006. New SHRIMP geochronology for the Western Fold Belt of the Mt Isa Inlier: developing a 1800-1650 Ma event framework. Australian Journal of Earth Sciences, 53, 1023-1039.

Nijman, W., Mijnlieff, H. F. \& Schalkwijk, G. $1992 a$. The Hero Fan Delta (Lower Mount Isa Group) and its structural control: deformation in the Hero/Western Fault Zone and Paroo Range compared, Proterozoic, Mount Isa Inlier, Queensland, Australia. In: Stewart, A. J \& Blake, D. H. (eds) Detailed Studies of the Mount Isa Inlier. Australian Geological Survey Organisation, Canberra, 243, 75-110.

Nijman, W., van Lochem, J. H., Spliethoff, H. \& FeiJTH, J. 1992b. Deformation model and sedimentation patterns of the Proterozoic of the Paroo Range, Mount Isa Inlier, Queensland, Australia. In: Stewart, A. J. \& Blake, D. H. (eds) Detailed Studies of the Mount Isa Inlier. Australian Geological Survey Organisation Bulletin 243, Canberra.

NortJe, G. S. 2009. Evolution and dynamics of fault controlled copper mineralization in the Mount Gordon Fault Zone, Mt Isa, Queensland, Australia. Unpublished $\mathrm{PhD}$ thesis, James Cook University, 369pp.

O'DeA, M. G. \& Lister, G. S. 1995. The role of ductility contrast and basement architecture in the structural evolution of the Crystal Creek Block, Mount Isa Inlier, NW Queensland, Australia. Journal of Structural Geology, 17, 949-960.

O’Dea, M. G., Lister, G. S., Betts, P. G. \& Pound, K. S. 1997. A shortened intraplate rift system in the Proterozoic Mount Isa Terrane, NW Queensland, Australia. Tectonics, 16, 425-441.

OJALA, V. J. \& NyKäNEN, V. 2007. Palaeo-stress modelling of the Central Lapland Greenstone Belt: Implications for gold exploration. In: OJALA, V. J (ed.) Gold in the Central Lapland Greenstone Belt, Finland. Geological Survey of Finland, Rovaniemi, Espoo, Special Paper, 44, 225-250.

Oliver, N. H. S., Butera, K. M. ET AL. 2008. The protracted hydrothermal evolution of the Mount Isa Eastern Succession: a review and tectonic implications. Precambrian Research, 163, 108-130.

Oliver, N. H. S., Cleverley, J. S. M. G., Pollard, P. J. F. B., Marshall, L. J. R. M. J. \& Williams, P. J. B. T. 2004. Modeling the role of sodic alteration in the genesis of iron oxide-copper-gold deposits, eastern Mount Isa Block, Australia. Economic Geology and the Bulletin of the Society of Economic Geologists, 99, 1145-1176.

Perkins, W. G. 1984. Mount Isa silica dolomite and copper orebodies: the result of a syntectonic hydrothermal alteration system. Economic Geology, 79, 601-637.

Perkins, W. G. 1989. Mount Isa copper orebodies; evidence against a cogenetic relationship with leadzinc. Abstracts of Seminars on North Queensland Mineral Deposits, 1973-1988, 5, 15.

Perkins, W. G. 1990. Mount Isa copper orebodies. Geology of the Mineral Deposits of Australia and Papua New Guinea, 14, 935-941.

Perkins, W. G. 1997. Mount Isa lead-zinc orebodies; replacement lodes in a zoned syndeformational copperlead-zinc system? Ore Geology Reviews, 12, 61-111.

Potts, G. J. \& Reddy, S. M. 1999. Construction and systematic assessment of relative deformation histories. Journal of Structural Geology, 21, 1245-1253.

Potts, G. J. \& Reddy, S. M. 2000. Application of younging tables to the construction of relative deformation histories-1: fracture systems. Journal of Structural Geology, 22, 1473-1490. 
RichaRdson, S. M. \& MoY, A. D. 1998. Gunpowder copper deposits. Geology of Australian and Papua New Guinean mineral deposits, 22, 743-752.

Rubenach, M. J. 2005. Tectonothermal evolution of the Eastern Fold Belt, Mt Isa Inlier. In: BLENKINSOP, T. G (ed.) Total Systems Analysis of the Mount Isa Eastern Succession, I 2+3 Final Report. Predictive Minerals Discovery Cooperative Research Centre.

Rubenach, M. J., Foster, D. R. W., Evins, P. M., Blake, K. L. \& Fanning, C. M. 2008. Age constraints on the tectonothermal evolution of the Selwyn Zone, Eastern Fold Belt, Mount Isa Inlier. Precambrian Research, 163, 81-107.

ScotT, K. M. \& TAYLOR, G. F. 1982. Eastern Creek Volcanics as the source of copper at the Mammoth Mine, northwest Queensland. Journal of Australian Geology and Geophysics, 7, 93-98.

Sibson, R. H. 1977. Fault rocks and fault mechanisms. Journal of the Geological Society, London, 133, 191-213.

Sibson, R. H. 1985. A note on fault reactivation. Journal of Structural Geology, 7, 751-547.

SiBSON, R. H. 1986. Brecciation processes in fault zones: inferences from earthquake rupturing. Pure and Applied Geophysics, 124, 159-174.

Sibson, R. H. 1989. Earthquake faulting as a structural process. Journal of Structural Geology, 11, 1-14.
SiBSON, R. H. 1996. Structural permeability of fluid-driven fault-fracture meshes. Journal of Structural Geology, 18, 1031-1042.

Sibson, R. H. 2000. Fluid involvement in normal faulting. Journal of Geodynamics, 29, 469-499.

Sibson, R. H. 2001. Seismogenic framework for hydrothermal transport and ore deposition. In: RichaRds, J. P. \& Tosdal, R. M (eds) Structural Controls on Ore Genesis. Reviews in Economic Geology. Society of Economic Geologists, Littleton, CO, 14, 25-47.

STEWART, A. J. 1992. The role of thrusting in the structural development of the Mount Isa Mine and its relevance to exploration in the surrounding region; discussion. Economic Geology and the Bulletin of the Society of Economic Geologists, 87, 1659-1664.

SwAGER, C. P. 1985. Syndeformational carbonatereplacement model for the copper mineralization at Mount Isa, Northwest Queensland; a microstructural study. Economic Geology and the Bulletin of the Society of Economic Geologists, 80, 107-125.

Swager, C. P., Perkins, W. G. \& Knights, J. G. 1987. Stratabound phyllosilicate zones associated with syntectonic copper orebodies at Mt. Isa, Queensland. Australian Journal of Earth Sciences, 34, 463-476.

Wilde, A., Jones, P. A., Gessner, K., Ailleres, L., Gregory, M. J. \& Duncan, R. 2006. A Geochemical Process Model for the Mount Isa Copper Orebodies. Economic Geology, 101, 1547-1567. 